ARTICLE

DOI: $10.1038 / s 41467-018-03147-6$

\title{
Host defense against oral microbiota by bone- damaging T cells
}

\author{
Masayuki Tsukasaki1, Noriko Komatsu', Kazuki Nagashima1', Takeshi Nitta (10 1, Warunee Pluemsakunthai', \\ Chisa Shukunami (10 ${ }^{2}$, Yoichiro Iwakura (1) ${ }^{3}$, Tomoki Nakashima ${ }^{4,5,6}$, Kazuo Okamoto ${ }^{7}$ \& Hiroshi Takayanagi ${ }^{1}$
}

The immune system evolved to efficiently eradicate invading bacteria and terminate inflammation through balancing inflammatory and regulatory T-cell responses. In autoimmune arthritis, pathogenic $\mathrm{T}_{\mathrm{H}} 17$ cells induce bone destruction and autoimmune inflammation. However, whether a beneficial function of T-cell-induced bone damage exists is unclear. Here, we show that bone-damaging $T$ cells have a critical function in the eradication of bacteria in a mouse model of periodontitis, which is the most common infectious disease. Bacterial invasion leads to the generation of specialized $T_{H} 17$ cells that protect against bacteria by evoking mucosal immune responses as well as inducing bone damage, the latter of which also inhibits infection by removing the tooth. Thus, bone-damaging $T$ cells, which may have developed to stop local infection by inducing tooth loss, function as a double-edged sword by protecting against pathogens while also inducing skeletal tissue degradation.

\footnotetext{
${ }^{1}$ Department of Immunology, Graduate School of Medicine and Faculty of Medicine, The University of Tokyo, 7-3-1, Hongo, Bunkyo-ku, 113-0033 Tokyo, Japan. ${ }^{2}$ Department of Molecular Biology and Biochemistry, Biomedical Sciences Major, Graduate School of Biomedical and Health Sciences, Hiroshima University, 1-2-3, Kasumi, Minami-ku, Hiroshima 734-8553, Japan. ${ }^{3}$ Research Institute for Biomedical Sciences, Tokyo University of Science, Yamazaki 2669 , Noda, Chiba 278-0022, Japan. ${ }^{4}$ Department of Cell Signaling, Graduate School of Medical and Dental Sciences, Tokyo Medical and Dental University, Yushima 1-5-45, Bunkyo-ku, Tokyo 113-8549, Japan. ${ }^{5}$ Japan Science and Technology Agency (JST), Precursory Research for Embryonic Science and Technology (PRESTO), Yushima 1-5-45, Bunkyo-ku, Tokyo 113-8549, Japan. ${ }^{6}$ Japan Agency for Medical Research and Development, Core Research for Evolutional Science and Technology (AMED-CREST), Yushima 1-5-45, Bunkyo-ku, Tokyo 113-8549, Japan. ${ }^{7}$ Department of Osteoimmunology, Graduate School of Medicine and Faculty of Medicine, The University of Tokyo, 7-3-1, Hongo, Bunkyo-ku, 113-0033 Tokyo, Japan. Correspondence and requests for materials should be addressed to H.T. (email: takayana@m.u-tokyo.ac.jp)
} 
T he interaction between host and microbial communities contributes to human health and disease ${ }^{1}$. The human body surface is mostly covered by an epithelial layer, a physical barrier that functions as the first line of defense against pathogen invasion as well as in response to commensal microbiota $^{1}$. The oral mucosa, however, is exceptional in that the teeth are effectively a trans-mucosal organ, and the interface between each tooth and the mucosa lacks integrity of tight junctions, making it susceptible to infection by oral bacteria ${ }^{2}$. Periodontitis affects $>47 \%$ adults in the U.S. ${ }^{3}$, and is considered one of the most frequent infectious diseases. Thus, unlike microbiota in other mucosal sites, such as gut and skin, the oral microbiota may have direct and distinct effects on the immune system as well as the health and well-being of the host.

The causal role of the oral microbiome in systemic diseases was first reported in 1891 by the American dentist Willoughby D. Miller". This concept was termed "oral sepsis" and led to the development of a focal infection theory, which was widely accepted until the middle of the twentieth century ${ }^{5}$. However, the theory was discredited and forgotten due to a lack of concrete evidence and ill-advised aggressive tooth extraction ${ }^{5}$. Recent studies have revisited the importance of the oral microbiota based on the close relationship between periodontitis and systemic pathological conditions, including cardiovascular disease, rheumatoid arthritis, adverse pregnancy outcomes, and diabetes ${ }^{6}$. Oral bacteria have been suggested to enter into the systemic circulation via inflamed gingiva and directly affect other organ ${ }^{6-9}$; therefore, the host may have a specialized defense system to protect against oral microbiota, but this mechanism has never been identified.

IL-17 and IL-17-producing $\mathrm{T}_{\mathrm{H}} 17$ cells play an important role in the host defense by inducing anti-bacterial peptides, recruiting neutrophils and promoting local inflammation through cytokines and chemokines ${ }^{10,11} \cdot \mathrm{T}_{\mathrm{H}} 17$ cells also contribute to the pathogenesis of various autoimmune diseases by causing prolonged inflammation and tissue damage $e^{10-13}$. In autoimmune arthritis, $\mathrm{T}_{\mathrm{H}} 17$ cells function as the exclusive bone-damaging T-cell subset that promotes osteoclastogenesis via the induction of receptor activator of NF- $\kappa B$ ligand (RANKL; encoded by the Tnfsf11 gene) on synovial fibroblasts through IL-17 production ${ }^{12,13}$. Pathogenic $\mathrm{T}_{\mathrm{H}} 17$ cells in arthritis have been shown to be converted from Foxp $^{+} \mathrm{T}$ cells ${ }^{14}$. The Foxp3 ${ }^{+}$T-cells-derived $\mathrm{T}_{\mathrm{H}} 17$ cells (exFoxp $3 \mathrm{~T}_{\mathrm{H}} 17$ cells) have a strong pro-inflammatory and proosteoclastogenic capacity, contributing to the pathogenesis of autoimmune arthritis ${ }^{14}$. This finding highlighted a crucial role of the plasticity of the $\mathrm{CD} 4^{+}$T-cell subsets under various inflammatory disorders ${ }^{14-19}$.

Here, we explore a beneficial function of T-cell-induced bone damage in a periodontitis model, in which exFoxp $3 \mathrm{~T}_{\mathrm{H}} 17$ cells contribute to protection against bacterial infection as well as induction of bone destruction. We show that periodontitis causes systemic bacterial dissemination in this model, an effect that is ameliorated by tooth extraction. This finding suggests that bonedamaging exFoxp $3 \mathrm{~T}_{\mathrm{H}} 17$ cells function to stop local infection by removing teeth. Thus, T-cell-mediated bone damage, which has been regarded merely as an adverse secondary effect of inflammation, may be a host defense mechanism against oral bacterial infection.

\section{Results}

Tooth loss stops systemic dissemination of oral bacteria. Periodontitis patients often develop bacteremia ${ }^{7,8}$, however, there has been little experimental evidence reported that shows oral bacteria translocate to other organs using animal models. We used a mouse model of periodontitis ${ }^{20}$ in which the placement of silk ligature around tooth leads to an accumulation of oral bacteria followed by inflammation and bone destruction. Livers, spleens, and the periodontal tissues were collected and analyzed after 42 days of periodontitis induction (Supplementary Fig. 1a). Notably, we detected bacterial colony formation in a culture of liver and spleen cells after persistent ligature placement around the tooth (Fig. 1a, b). The bacterial species detected in the liver and spleen were found in the oral cavity as well, but not in fecal samples (Fig. 1c), indicating systemic dissemination of oral bacteria during the breakdown of the oral barrier. Two weeks after periodontitis induction, the infected tooth became loose and easily dissociated from the jawbone due to osteoclastic resorption of the tooth-supporting bone (Supplementary Fig. 1b, c). We extracted the infected tooth and analyzed the local and systemic effects in an effort to elucidate the effects of tooth loss on the host. After tooth loss, the socket healed and became covered by the oral mucosa in less than 4 weeks (Supplementary Fig. 1), ending the systemic dissemination of oral bacteria (Fig. 1a, b) as well as the local inflammation in the oral mucosa (Fig. 1d). These results suggest that removal of an infected tooth by enhanced osteoclastic bone resorption is a host defense mechanism against the invasion of oral microbiota.

$T_{H} 17$ cell accumulation induced by oral microbiota. We thus hypothesized that the immune cells that direct osteoclastic bone erosion have a key role in the host defense against oral infection. Since $\mathrm{CD}_{4}^{+} \mathrm{T}$ cells have been shown to be essential for the periodontitis-induced bone loss[21], we investigated which subsets of $\mathrm{CD} 4^{+} \mathrm{T}$ cells were increased during oral infection. Among the $\mathrm{CD} 4^{+} \mathrm{T}$-cell subsets, $\mathrm{T}_{\mathrm{H}} 17$ cells exclusively accumulated in the oral mucosa and draining lymph nodes during oral infection (Fig. 2a-c, Supplementary Fig. 2), consistent with high expression of $\mathrm{T}_{\mathrm{H}}$ 17-related cytokines Il17a and Il6 in the oral mucosa of periodontitis-induced mice (Fig. 1d). In contrast, the frequency of Foxp $3^{+} \mathrm{T}$ cells was significantly decreased in the draining lymph nodes during periodontitis (Supplementary Fig. 2c). The number of neutrophils was significantly increased in the periodontal lesion, whereas the number of other immune cell populations (macrophages, dendritic cells, B cells or $\gamma \delta \mathrm{T}$ cells) was not increased, suggesting that the $\mathrm{T}_{\mathrm{H}} 17$ response is dominant in the inflamed gingiva (Supplementary Fig. 3). It has been reported that the physiological maintenance of $\mathrm{T}_{\mathrm{H}} 17$ cells in the oral tissue is not dependent on the microbiota but mastication-induced mechanical damage ${ }^{22}$. However, treatment with a broadspectrum antibiotic cocktail completely inhibited the accumulation of $\mathrm{T}_{\mathrm{H}} 17$ cells in the oral mucosa and draining lymph nodes in the periodontitis model (Fig. 2b, $\mathrm{c}$ and Supplementary Fig. 2e-g), indicating that the $\mathrm{T}_{\mathrm{H}} 17$ cell accumulation in the periodontal lesion is heavily dependent on the oral microbiota.

Induction of periodontal bone destruction by $T_{H} 17$ cells. $T_{H} 17$ cells are the exclusive osteoclastogenic $\mathrm{T}$-cell subset that promotes osteoclastogenesis via the induction of RANKL on mesenchymal cells, such as synovial fibroblasts, through IL-17 production ${ }^{12,13}$. However, the role of $\mathrm{T}_{\mathrm{H}} 17$ cells in oral infection-associated bone damage is obscure ${ }^{3}$. Despite the high expression of IL-17A in inflamed gingiva (Fig. 1d and Supplementary Fig. 4b), periodontitis-induced bone loss in $I l 17 a^{-1-}$ mice was comparable with that in wild-type mice (Supplementary Fig. 4a). The expression of IL-17F was increased in the inflamed gingiva in $I l 17 a^{-1-}$ mice (Supplementary Fig. 4c), potentially compensating for the IL-17A deficiency. Therefore, we used Il17a $a^{-1-} I l 17 f^{-1-}$ mice to investigate the role of $\mathrm{T}_{\mathrm{H}} 17$ cells and found that periodontal bone loss was significantly inhibited in $I 117 a^{-1-} I_{117 f^{-1}}$ mice (Fig. $2 \mathrm{~d}$, e). IL-17 is also produced by $\gamma \delta \mathrm{T}$ cells ${ }^{23}$; however, periodontitis-induced bone loss was suppressed in $\mathrm{Tcra}^{-/-}$mice 
a

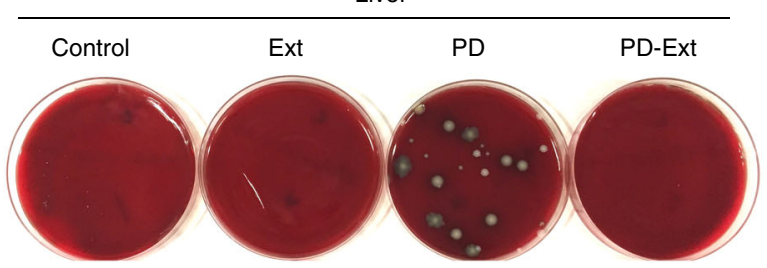

b
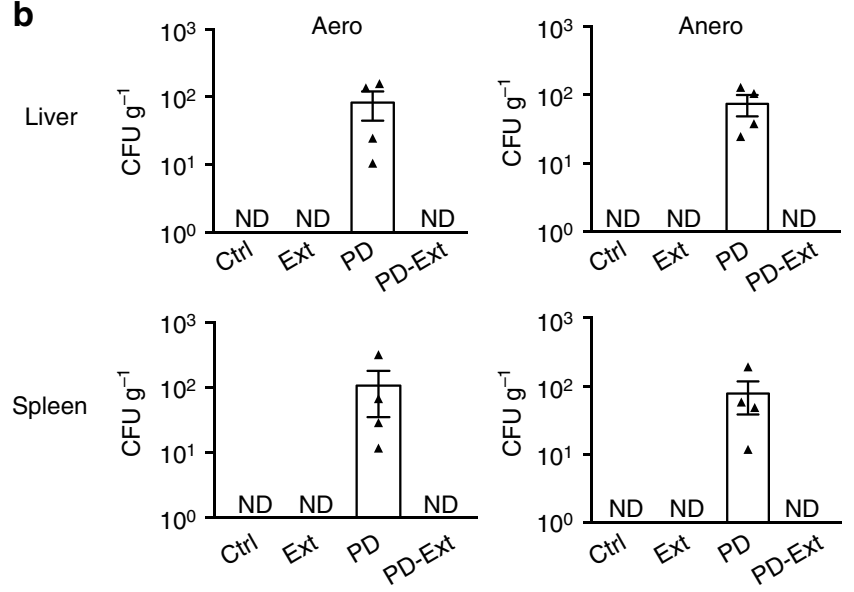

Spleen

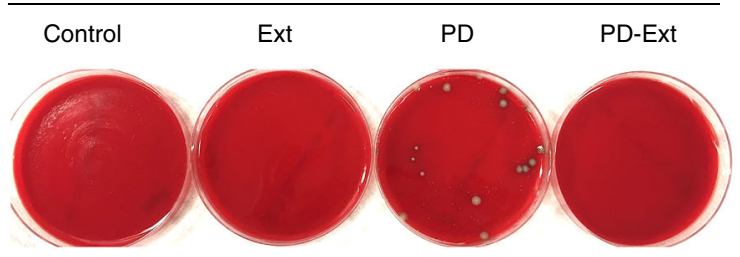

C

d
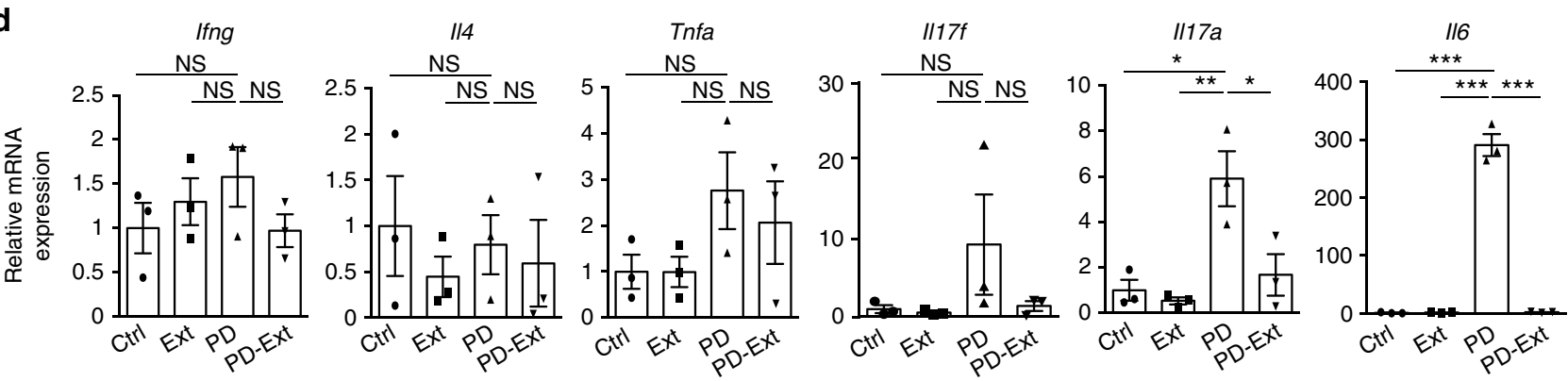

Fig. 1 Suppression of oral microbial invasion and local inflammation by tooth extraction. a Bacterial colony formation in the culture of the liver and spleen cells from mice subjected to an experimental periodontitis model (PD). This formation was abrogated by tooth extraction (PD-Ext). Colony formation was not observed in the control (Ctrl) or tooth-extracted (Ext) group. Representative pictures of more than three independent experiments are shown. $\mathbf{b}$ Colony-forming units (CFUs) in aerobic (Aero) and anaerobic (Anero) cultures of liver and spleen cells from mice in $\operatorname{Ctrl}(n=5)$, Ext $(n=4)$, PD $(n=4)$, or PD-Ext $(n=4)$ groups, pooled from two independent experiments. c 165 sequence analysis of tissue cultures, ligature (Oral), or fecal samples (Fecal) collected from a mouse in the PD group. The top fifteen frequently detected bacterial species in the aerobic liver culture are listed on the left and the sequence frequency (represented by the bottom bar) in each sample is shown. Representative data of more than three independent experiments is presented. d Quantitative RT-PCR analysis of inflammatory cytokines in the periodontal tissues collected from mice in the Ctrl, Ext, PD, or PD-Ext groups $(n=3)$. The data were obtained from duplicated experiments. All samples were collected at day 42 . All data are shown as the mean \pm s.e.m. Statistical analyses were performed using ANOVA with Tukey's multiple-comparison test. ${ }^{\star} P<0.05$; ${ }^{\star \star} P<0.01$; ${ }^{\star \star \star} P<0.005$; ND, not detected; NS, not significant

but not $\mathrm{Tcrd}^{-/-}$mice (Supplementary Fig. 4d), suggesting that $\mathrm{T}_{\mathrm{H}} 17$ cells rather than $\gamma \delta \mathrm{T}$ cells are involved in the bone damage during oral infection.

Regulation of oral microbiota by $\mathbf{T}_{\mathbf{H}} \mathbf{1 7}$ cells. Since IL-17 plays a key role in host defense against extracellular bacterial infections ${ }^{10}$, we monitored the quantity and composition of oral bacteria that accumulated at the inflammatory site in $I l 17 a^{-1-} I l 17 f^{-1-}$ mice. The total amount of bacterial DNA collected from the periodontal lesion was significantly increased in $I l 17 a^{-/-} I l 17 f^{-/-}$mice (Fig. 2f). Moreover, $16 \mathrm{~S}$ sequence analysis revealed that the composition of the oral bacteria was significantly altered in $I l 17 a^{-/} I l 17 f^{-/}$mice (Fig. 2g-i). The frequency of $\gamma$-proteobacteria, which predominantly colonizes peripheral tissues during the dissemination of oral bacteria (Fig. 1c), was increased in the oral cavity of $I l 17 a^{-/-} I l 17 f^{-/-}$mice (Fig. $2 \mathrm{~g}, \mathrm{~h}$ ). During the course of periodontitis in wild-type mice, the abundance of $\gamma$ proteobacteria in the inflammatory site was decreased at day 7 , when $\mathrm{T}_{\mathrm{H}} 17$ cells started to accumulate in the periodontal lesion (Supplementary Fig. 5). These results suggest that $\mathrm{T}_{\mathrm{H}} 17$ cells play a key role in host defense against the invasion of oral bacteria via the elimination of oral bacteria in addition to induction of bone loss.

Foxp3 $3^{+} \mathrm{T}$ cells convert into $\mathrm{T}_{\mathbf{H}} 17$ cells during oral infection. Next, we explored the origin of $\mathrm{T}_{\mathrm{H}} 17$ cells that accumulated in the periodontal lesion. $\mathrm{T}_{\mathrm{H}} 17$ cells are abundantly present in the small intestine lamina propria, especially in the terminal ileum ${ }^{24-26}$. Thus, we asked whether $\mathrm{T}_{\mathrm{H}} 17$ cells migrated from the small intestine to the periodontal tissues during oral infection. We 


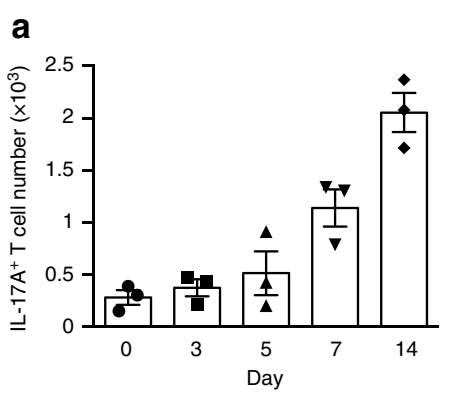

d
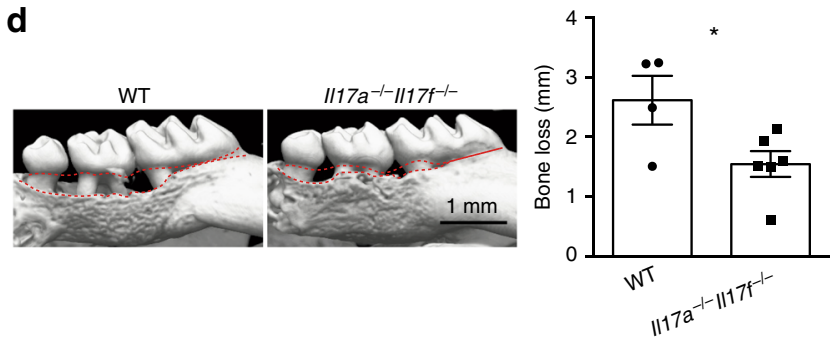

f

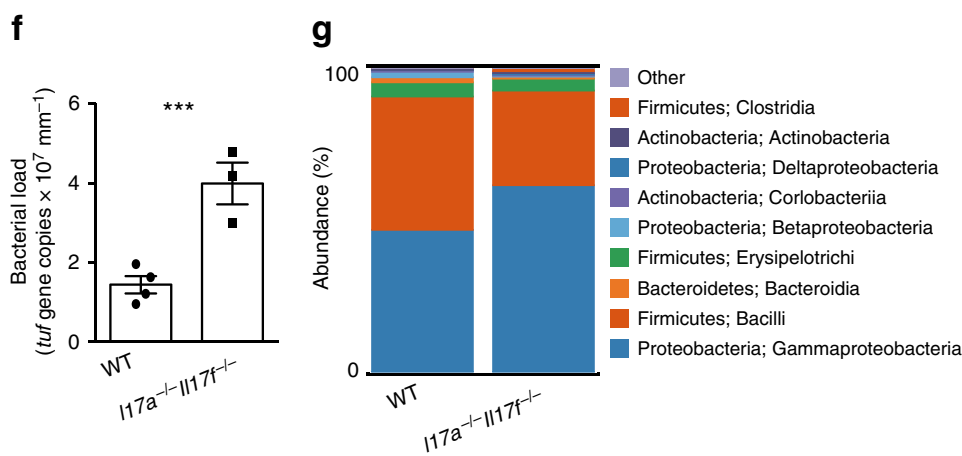

b

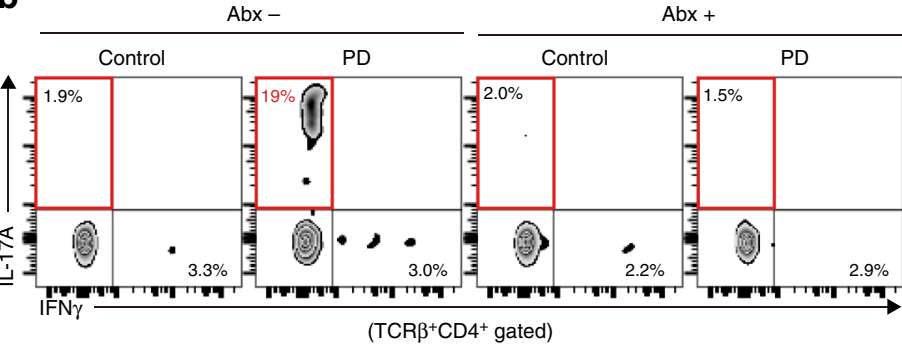

C

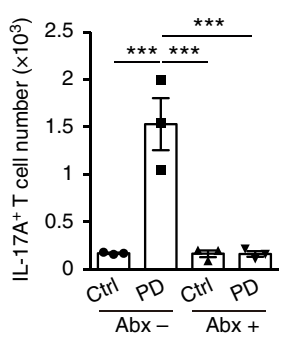

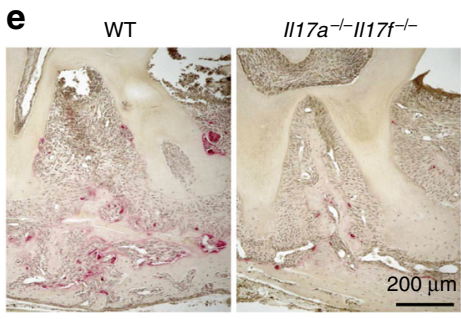

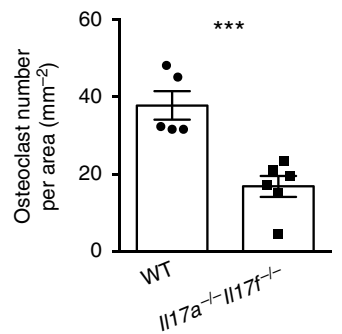

h

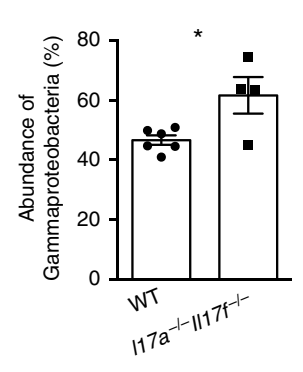

i

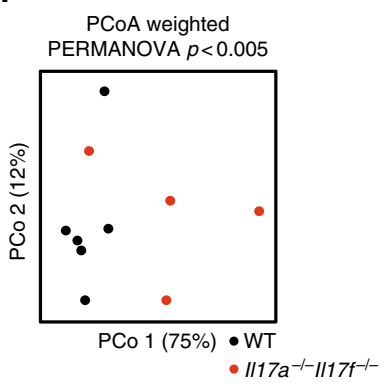

Fig. $2 T_{H} 17$ cells protect against the invasion of oral microbiota and induce bone damage. a Number of IL-17A ${ }^{+}$CD $4^{+}$TCR $\beta^{+}$cells in the periodontal tissues at various time points after the ligature placement $(n=3)$. Representative data of two independent experiments is presented. $\mathbf{b}, \mathbf{c}$ Effects of an antibiotic cocktail (Abx; ampicillin $1 \mathrm{mg} \mathrm{ml}^{-1}$, streptomycin $5 \mathrm{mg} \mathrm{ml}^{-1}$, and colistin $1 \mathrm{mg} \mathrm{ml}^{-1}$ in drinking water) on the accumulation of $\mathrm{T}_{H} 17$ cells. Mice were treated with Abx from 1 week before the ligature placement. The frequency $(\mathbf{b})$ and number $(\mathbf{c})$ of IL-17A ${ }^{+} \mathrm{CD} 4^{+} \mathrm{TCR} \beta^{+}$cells in the periodontal tissues were analyzed 7 days after the ligature placement $(n=3)$. PD: periodontitis. $\mathbf{d}$ Micro-CT analysis of periodontitis-induced bone loss in the wild-type $(n=4)$ or $\left\|17 a^{-/-}\right\| 17 f^{-/}$mice $(n=6)$, pooled from three independent experiments. The upper red dotted line indicates the cementoenamel junction and the lower red dotted line indicates the alveolar bone crest in the left panel. e Osteoclast number in the maxilla of the wild-type $(n=5)$ or $I / 17 a^{-/-} / 177 f^{-/-}$mice $(n=$ 6), pooled from two independent experiments. f Total bacterial load in ligatures collected from wild-type $(n=4)$ or $I 17 a^{-/-} \| 177 f^{-/-}$mice $(n=3)$. Representative data of two independent experiments is presented. $\mathbf{g}$ Oral bacterial composition (major phylum; class) of the wild-type $(n=6)$ or $I 117 a$ $-/-1 / 17 f^{-/}$mice $(n=4)$. h Abundance of $\gamma$-proteobacteria in the oral bacteria of the wild-type $(n=6)$ or $I 117 a^{-/-} \| 117 f^{-/-}$mice $(n=4)$. i Differences in the bacterial composition between the wild-type $(n=6)$ and $I 117 a^{-/-} I 117 f^{-/}$mice $(n=4)$. Principal coordinate analysis (PCoA) and permutational ANOVA (PERMANOVA) comparisons of the weighted Unifrac distances are shown. PCo1: principal coordinate 1; PCo2: principal coordinate 2. The data were pooled from two independent experiments $(\mathbf{g}-\mathbf{i})$. All data are shown as the mean \pm s.e.m. Statistical analyses were performed using ANOVA with Tukey's multiple-comparison test $(\mathbf{c})$, Student's $t$-test (d-f and $\mathbf{h}$ ) or PERMANOVA of the weighted Unifrac distances $(\mathbf{i}) .{ }^{\star} P<0.05 ;{ }^{\star \star \star} P<0.005$

utilized ROSA-CAG-lox-stop-lox-hKikGR $\times$ Vav-iCre mice in which violet light $(436 \mathrm{~nm})$ induces photoconversion of the KikGR protein from green (KikGR-green) to red (KikGR-red) in $V a v$-iCre-expressing haematopoietic lineage cells ${ }^{27}$. To track $\mathrm{T}_{\mathrm{H}} 17$ cell migration from the small intestine to the periodontal tissue, the mucosa of the terminal ileum was exposed to violet light $(436 \mathrm{~nm})$ under anesthesia at day 5 after periodontitis induction (Supplementary Fig. 6a). The mesenteric lymph nodes, cervical lymph nodes, and periodontal tissues were collected and analyzed at day 7 , when $\mathrm{T}_{\mathrm{H}} 17$ cells markedly accumulated in the periodontal tissues (Fig. 2a and Supplementary Fig. 6a). KikGR$\mathrm{red}^{+} \mathrm{T}$ cells were detected in the mesenteric lymph nodes, indicating that $\mathrm{T}$ cells migrated from the terminal ileum mucosa to the mesenteric lymph nodes (Supplementary Fig. 6b). In contrast, $\mathrm{T}_{\mathrm{H}} 17$ cells in the periodontal tissues or the draining lymph nodes were KikGR-red negative, indicating that $\mathrm{T}_{\mathrm{H}} 17$ cells in the inflamed gingiva were not originated from the small intestine (Supplementary Fig. $6 \mathrm{c}$ ). These results suggested that $\mathrm{T}_{\mathrm{H}} 17$ cells are locally expanded and/or differentiated in the periodontal lesion during oral infection.

It has been reported that the plasticity of the $\mathrm{CD} 4^{+} \mathrm{T}$-cell subsets has a key role under various inflammatory conditions ${ }^{14-}$ 19. Foxp3 $3^{+}$T-cells-derived $\mathrm{T}_{\mathrm{H}} 17$ cells, exFoxp $3 \mathrm{~T}_{\mathrm{H}} 17$ cells, have been shown to crucially contribute to the pathogenesis of asthma $^{17}$ and rheumatoid arthritis ${ }^{14}$. Interestingly, exFoxp $3 \mathrm{~T}_{\mathrm{H}} 17$ cells were shown to have the strongest pro-osteoclastogenic capacity among the $\mathrm{CD} 4^{+} \mathrm{T}$-cell subsets in vitro ${ }^{14}$. However, the role of exFoxp $3 \mathrm{~T}_{\mathrm{H}} 17$ cells in host immunity is unknown. We next investigated whether exFoxp $3 \mathrm{~T}_{\mathrm{H}} 17$ cells contribute to the host defense against oral bacteria. To monitor the loss of Foxp3 
a

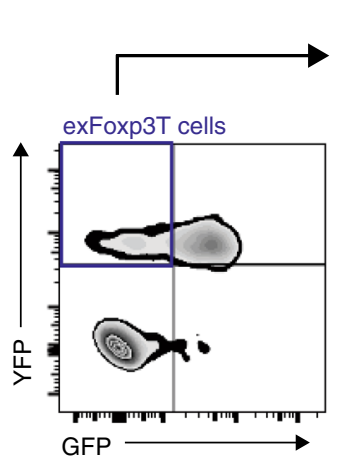

$\left(\mathrm{TCR} \beta^{+} \mathrm{CD} 4^{+}\right.$gated $)$

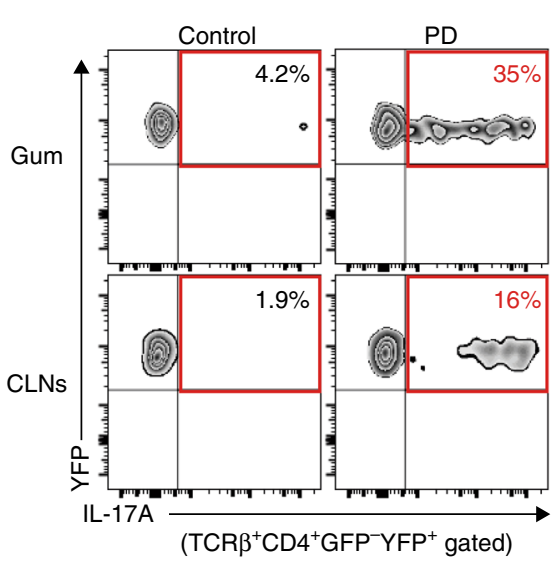

$\left(\mathrm{TCR} \beta^{+} \mathrm{CD} 4^{+} \mathrm{GFP}^{-} \mathrm{YFP}^{+}\right.$gated)
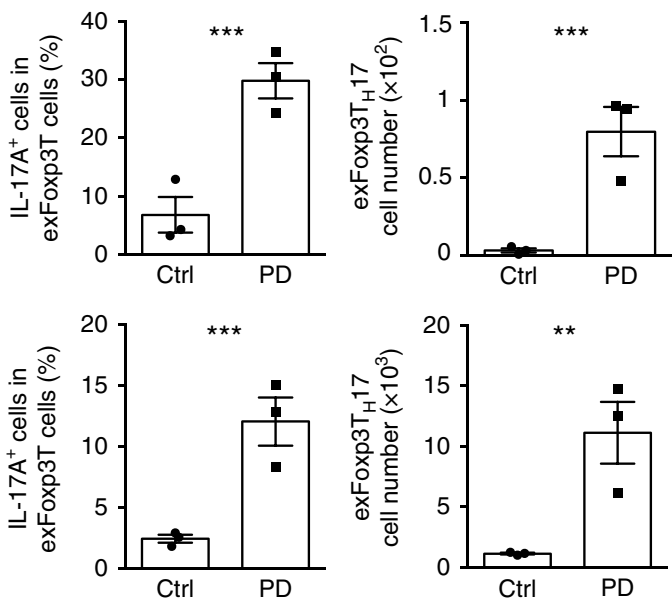

b
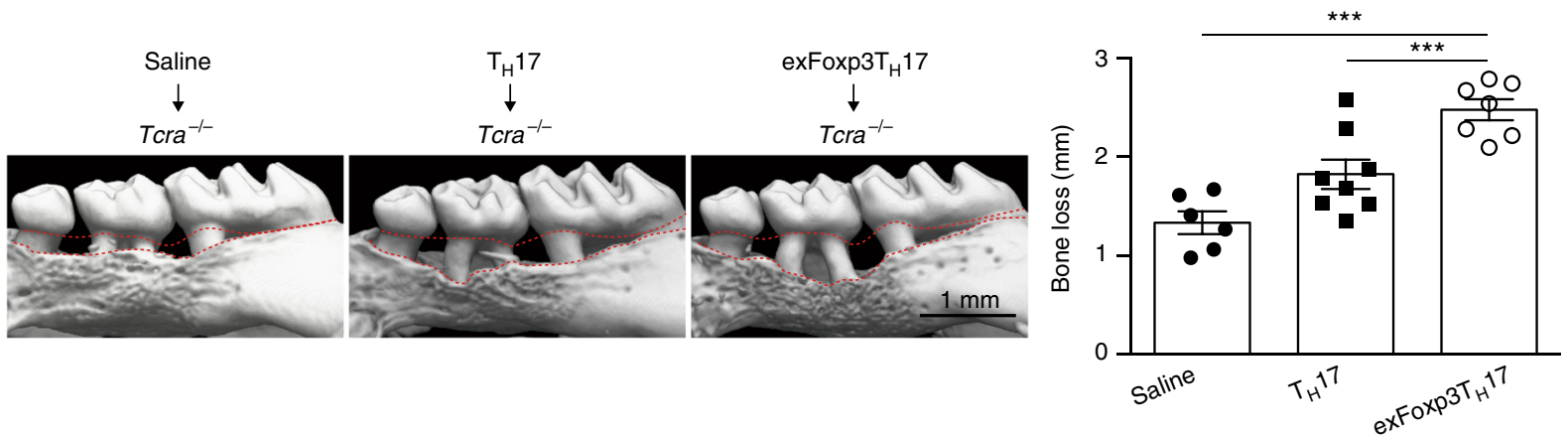

C

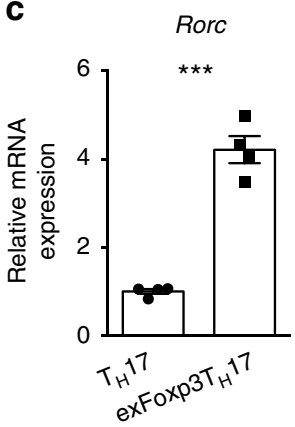

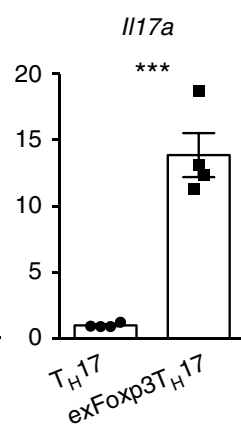

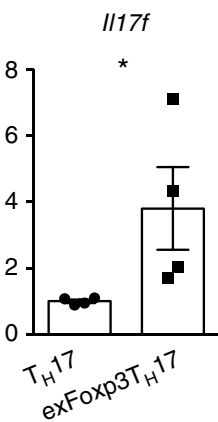

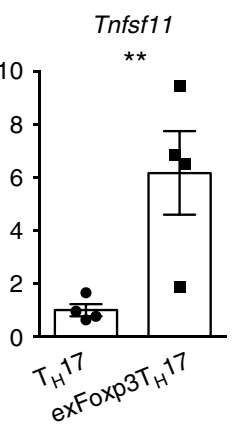

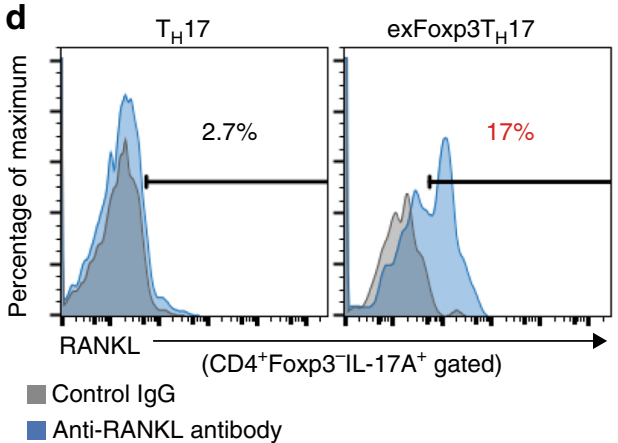

Fig. $3 \mathrm{~A}$ crucial role for exFoxp3T 17 cells in the bone destruction during oral infection. a Frequency and number of exFoxp3 $3 \mathrm{~T}_{H} 17$ cells in the periodontal tissues (Gum) and the cervical lymph nodes (CLNs) in control or periodontitis-induced mice 7 days after the ligature placement $(n=3)$. Representative data of more than three independent experiments is presented. PD: periodontitis. $\mathbf{b}$ Effects of adoptive transfer of $\mathrm{T}_{H} 17$ cells $(n=8)$ or exFoxp3TH 17 cells $(n=7)$ on periodontitis-induced bone loss compared to the saline group $(n=6)$. The data were pooled from more than three independent experiments. The upper red dotted line indicates the cementoenamel junction and the lower red dotted line indicates the alveolar bone crest in the left panel. All data are shown as the mean \pm s.e.m. c Quantitative RT-PCR analysis of Rorc, II17a, II17f, and Tnfsf11 transcripts in $T_{H} 17$ cells or exFoxp3TH17 cells $(n=4)$. The data were pooled from two independent experiments. d FACS profiles of RANKL expression in $T_{H} 17$ cells or exFoxp3T 17 cells. Representative data of more than three independent experiments is shown. Statistical analyses were performed using Student's $t$-test (a, $\mathbf{c}$ ), ANOVA with Tukey's multiple-comparison test (b). ${ }^{\star} P<0.05 ;{ }^{\star \star} P<0.01 ;{ }^{\star \star \star} P<0.005$

expression in vivo, we crossed Foxp3-GFP-Cre mice with ROSA26-YFP reporter mice, in which exFoxp3T cells are marked as $\mathrm{GFP}^{-} \mathrm{YFP}^{+}{ }_{\mathrm{T}}$ cells $^{14}$. We found that exFoxp3T cells in periodontitis-induced mice are characterized by a higher expression of RANKL and CCR6 than $\mathrm{GFP}^{-} \mathrm{YFP}^{-} \mathrm{T}$ cells (conventional T cells) (Supplementary Fig. 7a). exFoxp3T cells in periodontitisinduced mice expressed regulatory $\mathrm{T}\left(\mathrm{T}_{\text {reg }}\right)$ cell signature molecules such as GITR, KLRG1, FR4, and Nrp1 to a similar extent to $\mathrm{GFP}^{+} \mathrm{YFP}^{+} \mathrm{T}$ cells while $\mathrm{GFP}^{-} \mathrm{YFP}^{-} \mathrm{T}$ cells expressed these genes at a lower level (Supplementary Fig. 7c). exFoxp3Tcells also expressed OX40, CD25, CD39, CD103, Helios, and
CTLA-4, although to a lesser extent compared to $\mathrm{GFP}^{+} \mathrm{YFP}^{+}$ $\mathrm{T}$ cells (Supplementary Fig. 7b, c). These characteristics of exFoxp3T cells in periodontitis-induced mice are similar to those previously reported in arthritic mice ${ }^{14}$.

Fate mapping analysis further showed that the frequency and number of exFoxp3 $\mathrm{T}_{\mathrm{H}} 17$ cells to be markedly increased in the oral mucosa and draining lymph nodes during oral infection (Fig. 3a). Conversely, the frequency or number of IFN $\gamma$-expressing exFoxp3T cells (exFoxp3 $\mathrm{T}_{\mathrm{H}} 1$ cells) or IL-4-expressing exFoxp3 cells (exFoxp3 $\mathrm{T}_{\mathrm{H}} 2$ cells) was not increased (Supplementary Fig. 8). Adoptive transfer of exFoxp $3 \mathrm{~T}_{\mathrm{H}} 17$ cells into 
a
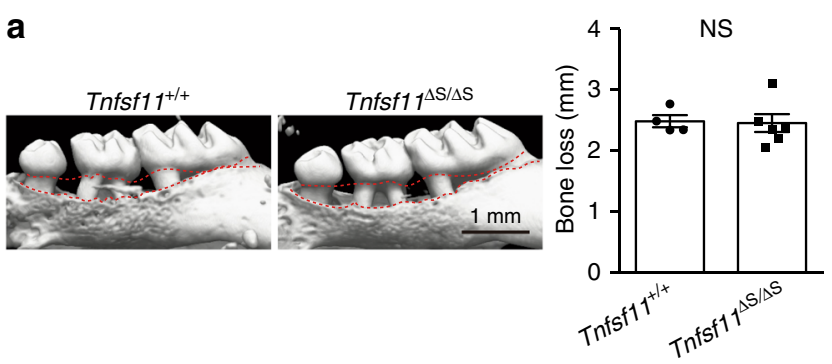

b
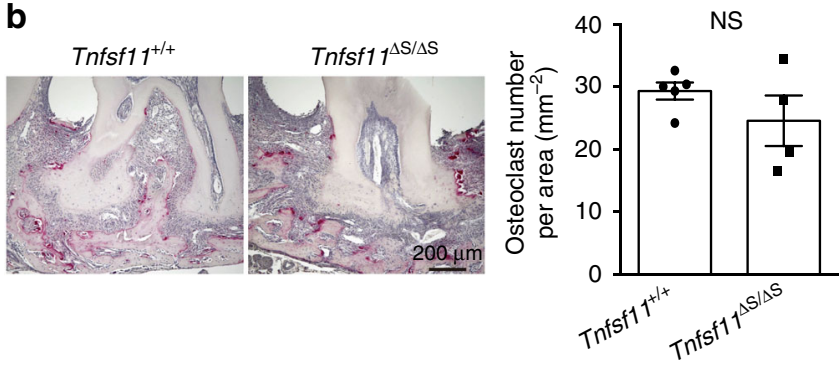

C

Control

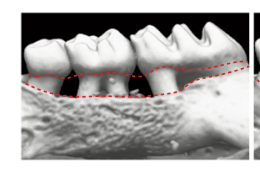

Mb1-Cre

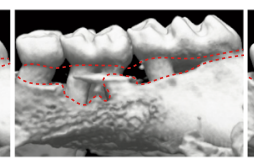

Cd4-Cre

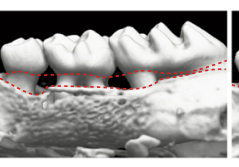

Scx-Cre

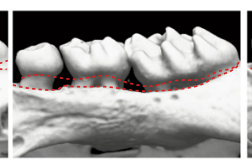

Sp7-Cre

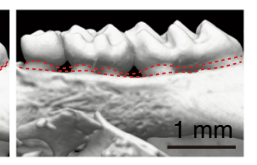

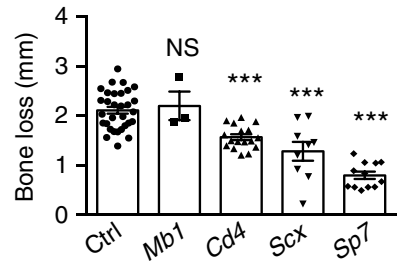

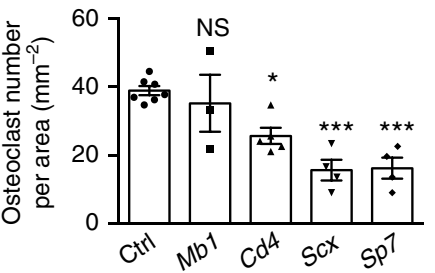

d

Control

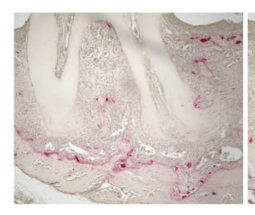

Mb1-Cre

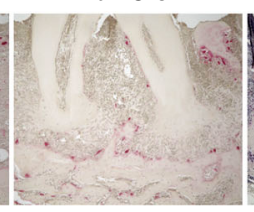

Cd4-Cre

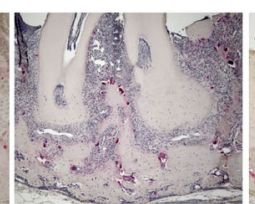

Scx-Cre

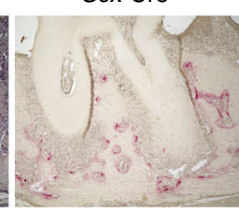

Sp7-Cre

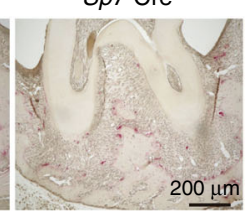

Fig. 4 Osteoblasts and periodontal ligament cells are the major source of RANKL in periodontitis. a Micro-CT analysis of periodontitis-induced bone loss in

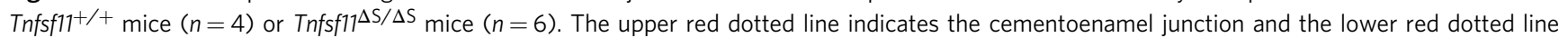
indicates the alveolar bone crest. b Histological analysis of periodontitis-induced osteoclast development in Tnfsf11 $1^{+/+}$mice $(n=5)$ or Tnfsf11 $\Delta S / \Delta S$ mice $(n=4)$. c Micro-CT analysis of periodontitis-induced bone loss in mice in which RANKL was specifically deleted in B cells $($ Mb1-Cre) ( $n=3)$, T cells (Cd4-Cre) $(n=17)$, periodontal ligament cells (Scx-Cre) $(n=9)$ or osteoblastic cells (Sp7-Cre) $(n=12)$ compared to control mice $(n=31)$. The upper red dotted line indicates the cementoenamel junction and the lower red dotted line indicates the alveolar bone crest in the left panel. $\mathbf{d}$ Osteoclast number in the maxilla of mice in which RANKL was specifically deleted in B cells (Mb1-Cre) $(n=3)$, T cells (Cd4-Cre) $(n=5)$, periodontal ligament cells (Scx-Cre) $(n=4)$ or osteoblastic cells (Sp7-Cre) $(n=4)$ compared to control mice $(n=7)$ evaluated by TRAP staining. The data were pooled from more than three independent experiments $(\mathbf{c}, \mathbf{d})$. All data are shown as the mean \pm s.e.m. Statistical analyses were performed using Student's $t$-test (a, b), ANOVA with Dunnett's multiple-comparison test (c, d). ${ }^{\star} P<0.05 ;{ }^{\star \star \star} P<0.005$; NS, not significant

$\mathrm{Tcra}^{-/-}$mice significantly promoted periodontitis-induced bone loss compared with the transfer of conventional $\mathrm{T}_{\mathrm{H}} 17$ cells or saline controls (Fig. $3 \mathrm{~b}$ and Supplementary Fig. 9). Interestingly, exFoxp $3 \mathrm{~T}_{\mathrm{H}} 17$ cells in periodontitis-induced mice had much higher expression levels of effecter molecules such as Rorc, Il17a, Ill7f, and Tnfsf 11 than conventional $\mathrm{T}_{\mathrm{H}} 17$ cells (Fig. $3 \mathrm{c}$ ). exFoxp $3 \mathrm{~T}_{\mathrm{H}} 17$ cells expressed high amounts of membrane-bound RANKL even in the absence of in vitro stimulation (Fig. 3d).

Identification of the source of RANKL in periodontitis. Although RANKL is mainly functional in its membrane-bound form ${ }^{28}$, the soluble RANKL produced by activated B cells and $\mathrm{T}$ cells has been proposed to play a major role in periodontal bone $\operatorname{loss}^{29}$. Which type of RANKL is critical and which cell type(s) is the main source of RANKL in periodontitis-induced bone damage? To reveal the role of soluble RANKL to periodontal bone loss, we exploited Tnfsf $11^{\Delta \mathrm{S} / \Delta \mathrm{S}}$ mice, in which the soluble form of RANKL is absent and thus only membrane-bound RANKL exists ${ }^{30}$. We found that there was no difference in periodontitis-induced bone loss between Tnfsf $11^{\Delta \mathrm{S} / \Delta \mathrm{S}}$ mice and wild-type mice (Fig. 4a, b), showing that the contribution of soluble RANKL is negligible. Thus, RANKL-producing cells should directly interact with osteoclast precursors in a cell-cell contact manner. In situ hybridization revealed that RANKL was expressed in mesenchymal cells including osteoblastic cells and periodontal ligament cells as well as hematopoietic cells adjacent to alveolar bone during periodontal inflammation (Supplementary Fig. 10).

We crossed Tnfsf $11^{\text {flox/flox }}$ mice with various Cre lines specific to B cells, T cells, osteoblastic cells and periodontal ligament cells to investigate the source of RANKL in periodontitis ${ }^{31}$. Since RANKL on osteoblastic cells is essential for tooth eruption ${ }^{32}$, we used a $S p 7$-tTA-tetO-Cre $(S p 7-C r e)$ system in which Cre recombinase is expressed only when a tetracycline-controlled transactivator (tTA) binds to a tetracycline responsive element (tetO) in the absence of doxycycline (Dox $)^{33}$. Sp7-Cre mice crossed with RANKL-floxed mice were treated from the prenatal period with Dox, which was withdrawn at the age of 3 weeks. Periodontitis was induced at the age of 8 weeks and alveolar bone was analyzed 10 days after the ligature placement in all groups. We found that periodontitis-induced bone loss and osteoclast number were markedly suppressed when RANKL was deleted in osteoblastic cells (Sp7-Cre) and periodontal ligament cells (ScxCre) (Fig. 4c, d). Osteoblastic cells and periodontal ligament cells reportedly express RANKL in response to IL-17 (refs. ${ }^{34,35}$ ). The periodontitis-induced bone loss and osteoclast number were significantly reduced, albeit to a lesser extent, when RANKL was deleted in T cells (Cd4-Cre) but not B cells (Mb1-Cre) (Fig. 4c, d). Thus, it is likely that exFoxp $3 \mathrm{~T}_{\mathrm{H}} 17$ cells contribute to bone loss by inducing RANKL expression mainly on osteoblastic cells and periodontal ligament cells via IL-17 production. 

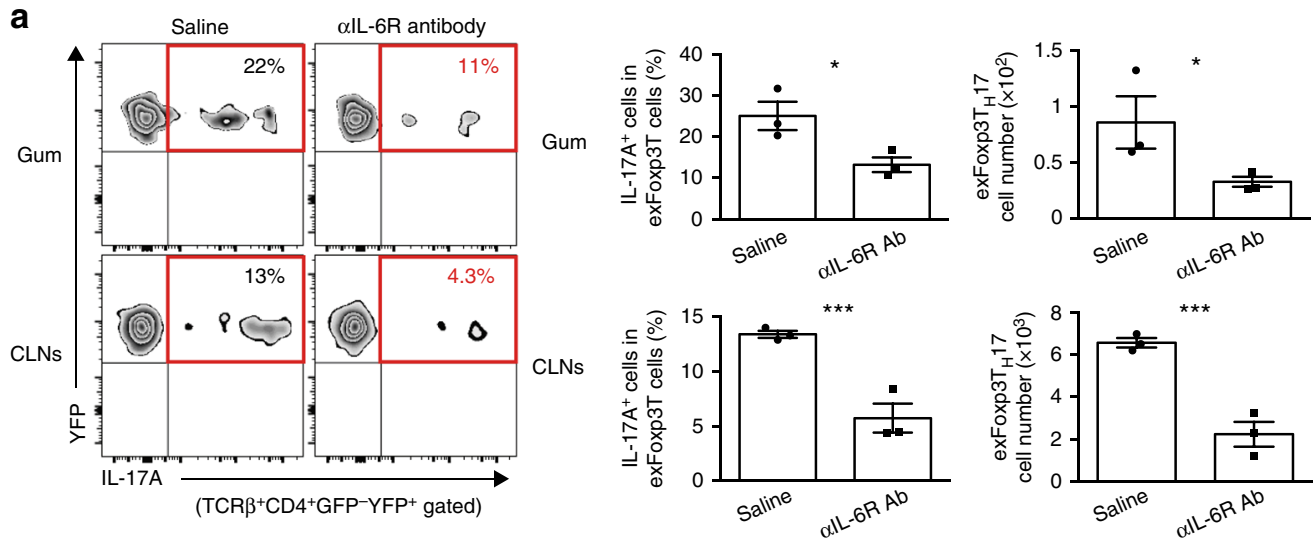

b
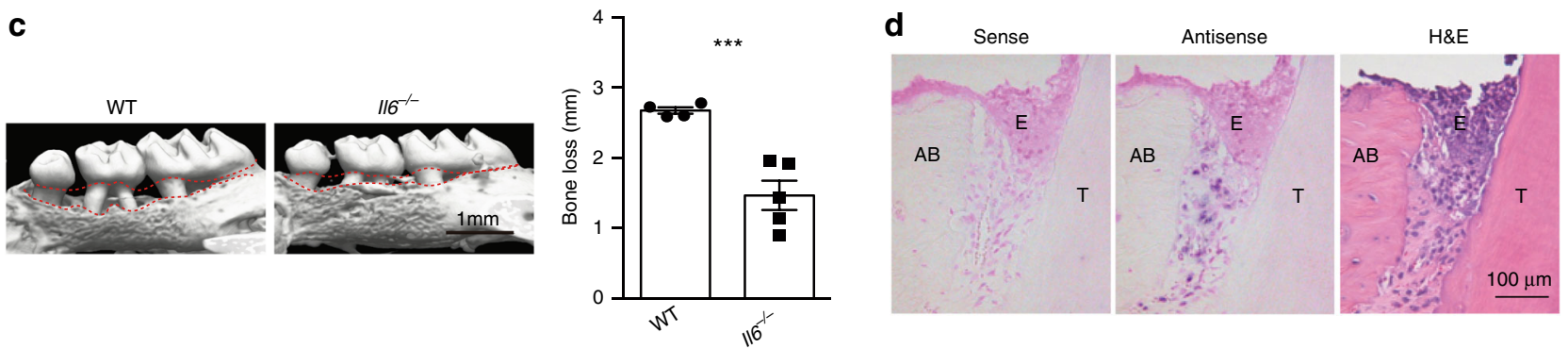

Fig. 5 IL-6 facilitates the generation of exFoxp3T 17 cells during periodontal infection. a Frequency and number of exFoxp $3 \mathrm{~T}_{\mathrm{H}} 17$ cells in periodontal tissues (Gum) and cervical lymph nodes (CLNs) in periodontitis-induced mice treated with saline or anti-IL-6R antibody (Ab) 7 days after the ligature placement $(n=3)$. Two milligrams of anti-IL-6R Ab (MR16-1) were injected intraperitoneally after 2 days of the ligature placement. Representative data of two independent experiments is shown. b Periodontitis-induced bone loss in control mice or anti-IL-6R Ab-treated mice $(n=5)$, pooled from two independent experiments. c Micro-CT analysis of periodontitis-induced bone loss in wild-type mice $(n=4)$ or $116^{-/-}$mice $(n=5)$. The upper red dotted line indicates the cementoenamel junction and the lower red dotted line indicates the alveolar bone crest. $\mathbf{d}$ In situ hybridization of 116 mRNA in periodontitis-induced wild-type mice 3 days after the ligature placement. Representative data of more than three independent experiments is shown. H\&E, haematoxylin and eosin stain; $E$, epithelium; $T$, tooth; $A B$, alveolar bone. All data are shown as the mean \pm s.e.m. Statistical analyses were performed using Student's $t$-test. ${ }^{\star} P<0.05 ;{ }^{* \star *} P<0.005$

IL-6 induces the generation of exFoxp $3 \mathrm{~T}_{\mathrm{H}} 17$ cells. The conversion from Foxp $3^{+} \mathrm{T}$ cells into exFoxp $3 \mathrm{~T}_{\mathrm{H}} 17$ cells was shown to be dependent on the IL-6 signaling pathway in vitro ${ }^{14}$, so we investigated whether the development of exFoxp3 $\mathrm{T}_{\mathrm{H}} 17$ cells at the oral barrier is also mediated by IL- 6 in vivo. Treatment with anti-IL-6 receptor (IL-6R) antibody significantly inhibited the generation of exFoxp3 $\mathrm{T}_{\mathrm{H}} 17$ cells (Fig. 5a) as well as bone loss in periodontitis-induced mice (Fig. 5b). IL-6-deficient mice were also resistant to periodontal bone loss (Fig. 5c). Periodontitisinduced $I l 17 a$ expression in the oral mucosa was completely inhibited in $I 6^{-/-}$mice (Supplementary Fig. 11a). The expression of Rorc in $\mathrm{CD}^{+} \mathrm{T}$ cells sorted from cervical lymph nodes was increased during periodontitis in wild-type mice, but not in $\mathrm{Il}^{-/-}$ mice (Supplementary Fig. 11b). These results indicated that IL-6 signaling is essential for the induction of $\mathrm{T}_{\mathrm{H}} 17$ cells and exFoxp $3 \mathrm{~T}_{\mathrm{H}} 17$ cells during oral infection. Although gingival epithelial cells are reportedly a major producer of IL-6 in mastication-induced $\mathrm{T}_{\mathrm{H}} 17$ cell development in the oral mucosa ${ }^{22}$, IL-6 expression was detected at the periodontal ligament site but not the epithelium in the periodontitis model (Fig. 5d).

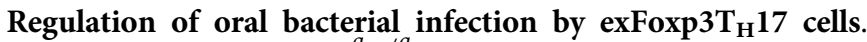
Finally, we crossed Il6raflox/flox mice with Foxp3-Cre mice in order to specifically deplete exFoxp $3 \mathrm{~T}_{\mathrm{H}} 17$ cells $^{17}$. Similar to the phenotype seen in $I l 17 a^{-1-} I l 17 f^{-1-}$ mice (Fig. 2d-i), Il6raflox/flox Foxp3-Cre mice displayed milder bone loss but increased bacterial load compared with control mice during periodontal infection (Fig. 6a-c). In addition to $I l 17 a$ and $T n f s f 11$, the expression levels of inflammatory cytokines $I l 6$ and $I l 1 b$, the antimicrobial peptides Defbl and Defb4, and the neutrophil chemo-attractants $\mathrm{Cxcl} 1$ and $\mathrm{Cxcl} 2$ were significantly suppressed in the absence of exFoxp $3 \mathrm{~T}_{\mathrm{H}} 17$ cells during periodontal infection (Fig. 6d). Furthermore, the bacterial composition was significantly altered in the oral cavity of Il6raflox/flox Foxp3-Cre mice (Fig. 6e-g). The frequency of $\gamma$-proteobacteria was increased in the Il6raflox/flox Foxp3-Cre mice (Fig. 6e, f), consistent with our observations in the $I l 17 a^{-/-} I l 17 f^{-1-}$ mice (Fig. 2g, h). Since IL-17 has been shown to induce the expression of defensins and chemokines in intestinal epithelial cells to regulate gut microbiota ${ }^{10}$, it is likely that exFoxp $3 \mathrm{~T}_{\mathrm{H}} 17$ cells control the quantity and quality of oral bacteria via the induction of antimicrobial peptides and chemokines in the gingival epithelial cells by IL-17 during oral infection. Collectively, the data show a crucial role for the conversion of Foxp3 $3^{+} \mathrm{T}$ cells into exFoxp $3 \mathrm{~T}_{\mathrm{H}} 17$ cells in host immunity against oral microbiota (Supplementary Fig. 12).

\section{Discussion}

Here, we show that bone-damaging $\mathrm{T}$ cells, $\mathrm{T}_{\mathrm{H}} 17$ cells converted from Foxp $3^{+} \mathrm{T}$ cells, orchestrate the host defense against oral microbiota by regulating both osteoclastic bone resorption and antimicrobial immunity. Needless to say, the teeth comprise an essential, non-substitutable organ that are not typically extracted to prevent infection in modern times since oral infection is controllable by dental interventions ${ }^{36}$. In periodontitis patients, 
a

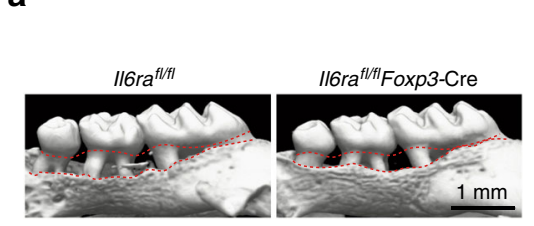

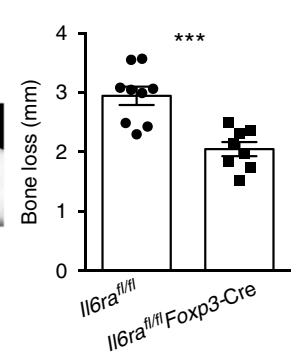

b

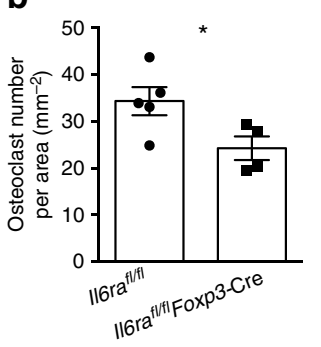

c

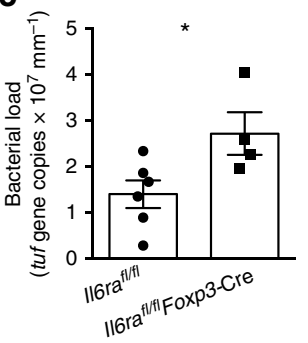

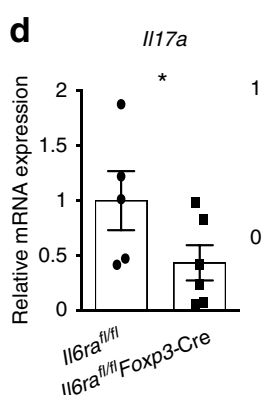

e

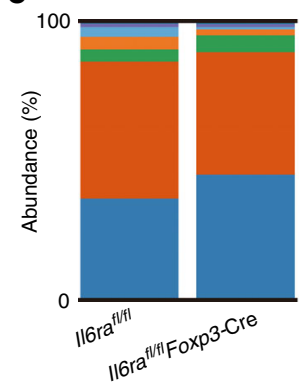

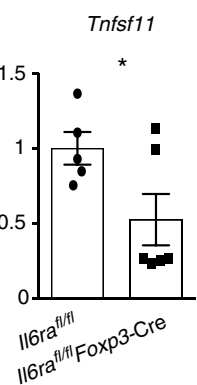

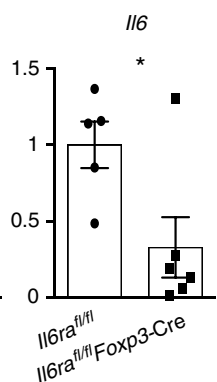

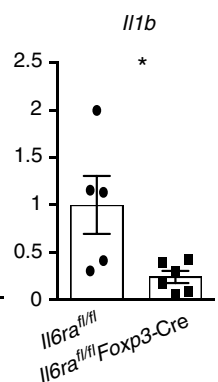

f

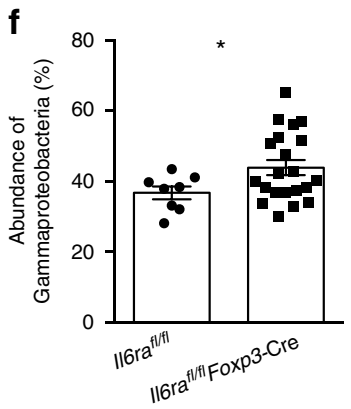

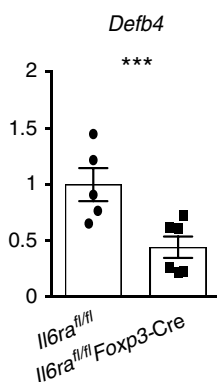
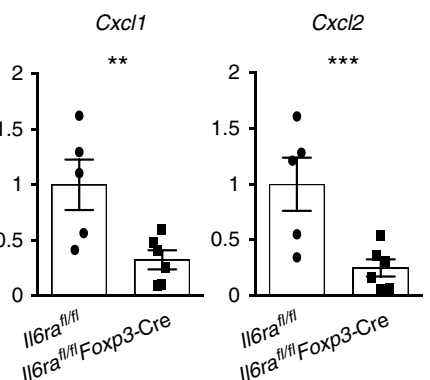

g

PCoA weighted

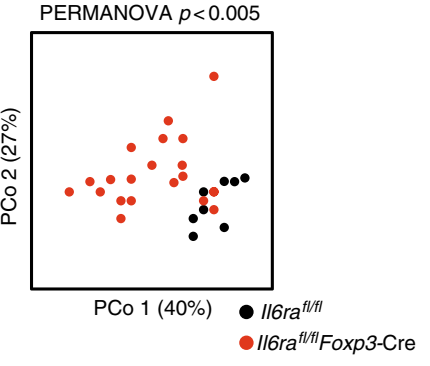

Fig. 6 Induction of anti-bacterial response and bone damage by exFoxp3T 17 cells. a Micro-CT analysis of periodontitis-induced bone loss in $/ 16$ a flox/flox mice $(n=9)$ or $116 \mathrm{ra}^{\text {flox/flox }}$ Foxp3-Cre mice $(n=8)$. The upper red dotted line indicates the cementoenamel junction and the lower red dotted line indicates the alveolar bone crest. $\mathbf{b}$ Number of osteoclasts in the maxilla of periodontitis-induced $\| 6 \mathrm{raflox}^{\text {flox }}$ mice $(n=5)$ or $\| 6 \mathrm{ra}{ }^{\text {flox}} /$ flox Foxp3-Cre mice $(n=4)$, pooled from two independent experiments. c Total bacterial load determined by analyzing the tuf gene copy number in ligatures collected from $/ 16 \mathrm{raflox} / f l o x$

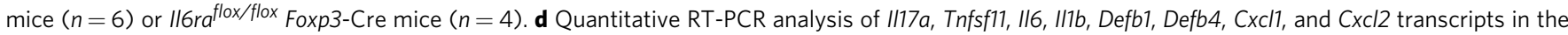
periodontal tissues collected from periodontitis-induced $116 \mathrm{ra} \mathrm{flox}_{\text {flox }}$ mice $(n=5)$ or $116 \mathrm{ra} \mathrm{flox}^{\mathrm{f} / \mathrm{flox}}$ Foxp3-Cre mice $(n=6)$. The data were obtained from duplicated experiments. e Bacterial composition (major phylum; class) of DNA collected from ligatures of $/ 16 \mathrm{raflox} /$ flox mice $(n=8)$ or $\| 6 \mathrm{ra}$ flox/flox Foxp3-Cre mice $(n=20)$. f Abundance of $\gamma$-proteobacteria in the bacterial DNA collected from the ligatures of $\| 6 \mathrm{ra}^{\text {flox } / f l o x}$ mice $(n=8)$ or $\| 6 \mathrm{ra}{ }^{\text {flox } / f l o x}$ Foxp3-Cre mice

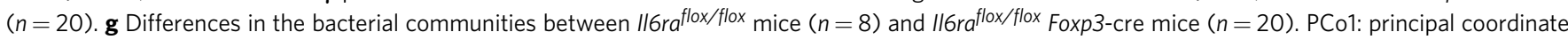
1; PCo2: principal coordinate 2. The data were pooled from more than three independent experiments (e-g). PERMANOVA comparisons of the weighted Unifrac distances are shown. All data are shown as the mean \pm s.e.m. Statistical analyses were performed using Student's $t$-test (a-d and $\mathbf{f}$ ) or PERMANOVA of the weighted UniFrac distances $(\mathbf{g}) .{ }^{\star} P<0.05 ;{ }^{\star \star} P<0.01$; ${ }^{\star \star \star} P<0.005$

teeth with severe infections are eventually lost due to the resorption of tooth-supporting bone, resulting in a complete resolution of infection and inflammation. In contrast, osteopetrotic patients with periodontal infection develop severe osteomyelitis of the jaw, which is treated by tooth extraction and antibiotic treatment ${ }^{37}$. These observations support the concept that inflammatory bone loss is crucial for the termination of oral infection.

One of the most serious side effects of anti-bone resorptive drugs (e.g., bisphosphonate and anti-RANKL antibody) is osteonecrosis of the jaw $(\mathrm{ONJ})^{38}$. Intriguingly, the osteonecrosis is observed only in the jaw, probably due to the unique feature of the jawbone where teeth are embedded and easily exposed to the oral bacterial invasion. Tooth extraction has been thought as a potential trigger for the onset of $\mathrm{ONJ}^{38}$. However, recent studies have shown that local infection, but not tooth extraction itself, is a key risk factor for the development of $\mathrm{ONJ}^{39,40}$. It has recently been suggested that tooth extraction aiming at the eradication of a local infection may decrease the risk for the development of ONJ [39]. The concept of tooth loss as the host defense mechanism presented in this study may provide additional insights into the understanding of the pathogenesis of ONJ.

$\mathrm{T}_{\mathrm{H}} 17$ cells are abundantly present in the human periodontal lesion ${ }^{3}$ and shown to be the major cellular source of IL-17 in the periodontal tissues of periodontitis patients ${ }^{41}$. The levels of IL-17 in the periodontal tissues correlate with the severity of periodontitis in humans ${ }^{42}$. Importantly, Foxp $3^{+} \mathrm{IL}^{-17^{+}}$cells, which apparently are in the transition state during the conversion, were observed in the periodontal tissues obtained from severe periodontitis patients ${ }^{43}$, suggesting that exFoxp $3 \mathrm{~T}_{\mathrm{H}} 17$ cells may play a key role in the pathogenesis of human periodontitis.

The generation of exFoxp $3 \mathrm{~T}_{\mathrm{H}} 17$ cells in the oral mucosa is heavily dependent on IL-6 signaling pathway (Fig. 5a). A clinical study showed that tocilizumab, an IL-6R inhibitor, significantly 
ameliorated periodontal inflammation ${ }^{44}$. The IL-6 messenger RNA (mRNA) was highly expressed in the periodontal ligament cells during periodontitis (Fig. 5d). It has been reported that IL-6 production by periodontal ligament fibroblasts is stimulated by bacteria (e.g., Porphyromonas gingivalis, Prevotella intermdedia, Fusobacterium nucleatum, Aggregatibacter actinomycetemcomitans and Escherichia coli) and pathogen-associated molecular patterns (PAMPs) (e.g., lipopolysaccharides (LPS), peptidoglycan (PGN), muramyl dipeptide (MDP), L-Ala- $\gamma$-D-Glu-mDAP (TriDAP) and Pam3CysSerLys4 (Pam3CSK4) $)^{45-50}$. Thus, oral bacteria and their components may directly stimulate IL-6 production by periodontal ligament fibroblasts during periodontitis. Collectively, fine-tuning of bone-damaging $\mathrm{T}$ cells with an appropriate control of oral infection may be a promising strategy to prevent periodontitis-induced bone and tooth loss.

The mechanisms of inflammatory bone destruction have been intensively investigated in the field of rheumatoid arthritis ${ }^{12}$. In autoimmune arthritis, pathogenic $\mathrm{T}_{\mathrm{H}} 17$ cells that induce bone destruction are also causative of autoimmune inflammation. However, it has never been properly elucidated why the activation of host immunity is designed so as to induce bone damage. Among the inflammatory bone disorders, alveolar bone loss due to oral infection is most commonly observed in the vertebrates, including ancient reptiles ${ }^{51}$, in which teeth are constantly replaced. Although teeth are essential for eating and fighting in mammals, we speculate that inflammatory bone erosion followed by tooth loss is a primitive host defense mechanism to prevent prolonged bacterial invasion, a mechanism, which has been evolutionarily conserved from animals with replaceable teeth to humans. Indeed, the Tnfsf11 and Il17a genes are widely conserved across species ranging from jawed fishes to humans ${ }^{52}$.

The symbiotic relationship between gut microbiota and host is tightly regulated by the intestinal barrier function ${ }^{1}$. In contrast, oral microbiota easily flow into the bloodstream via the inflamed gingiva. Thus, the oral microbiota have the capacity to impact systemic health in a manner distinctly different from the gut microbiota. Our study highlights a unique host defense system against microorganisms in which the immune and skeletal systems cooperate, extending the horizon of host-microbiome interactions.

\begin{abstract}
Methods
Mice. All animals were maintained under specific pathogen-free conditions, and all experiments were performed with the approval of the Institutional Review Board at The University of Tokyo. C57BL/6 mice were purchased from CLEA Japan. Foxp3YFP-Cre mice, Il6ra flox/flox mice were obtained from the Jackson Laboratory. Foxp $3^{h C D 2}$ knock-in mice ${ }^{14,53}$, Il17a-GFP knock-in mice ${ }^{14}$, Foxp3-GFP-Cre mice ${ }^{14}$, ROSA26-loxP-Stop-loxP-YFP reporter mice ${ }^{14}, I l 17 a^{-/-}$mice $^{10}, I l 17 f^{-/-}$mice $^{10}$, Tnfsf11 flox/flox mice ${ }^{30}$, Tnfsf $11^{\Delta \mathrm{S} / \Delta \mathrm{S}}$ mice $^{30}$, Scx-Cre mice ${ }^{54,55}$, Cd4-Cre mice ${ }^{56}$, Mb1-Cre mice ${ }^{57}$, Sp7-Cre mice ${ }^{33}, I l^{-1-}$ mice $^{33}$, Tcrd $^{-1-}$ mice $^{23}, \mathrm{Tcra}^{-/-}$mice $^{58}$, ROSA-CAG-lox-stop-lox-hKikGR mice ${ }^{27}$, and $V a v$-iCre mice ${ }^{59}$ were described previously. Eight- to 16-week-old sex-matched mice were used for all of the experiments unless otherwise noted.
\end{abstract}

Ligature-induced periodontitis model. To evaluate the periodontitis-induced bone loss, a 5-0 silk ligature was tied around the maxillary left second molar and the contralateral tooth was left unligated to serve as the baseline control, as described previously ${ }^{20}$. The distance between the cementoenamel junction and alveolar bone crest (CEJ-ABC distance) was measured for six predetermined maxillary sites on both the buccal and palatal sides ${ }^{20}$. The mice were sacrificed and analyzed 10 days after placement of the ligature unless otherwise indicated. The maxillae were subjected to micro-CT and histological analyses, respectively. For micro-CT analysis, the maxillae were fixed with $70 \%$ ethanol until analysis. MicroCT scanning was performed with a ScanXmate-A100S Scanner (Comscantechno). Three-dimensional microstructural image data were reconstructed and structural indices were calculated using TRI/3D-BON software (RATOC). For histological analyses, the maxillae fixed by $4 \%$ paraformaldehyde underwent decalcification in OSTEOSOFT $^{\circledast}$ (Merk Millipore) for 3 weeks and were embedded in paraffin after dehydration. Sections were stained with tartrate-resistant acid phosphatase (TRAP) and TRAP-positive multinucleated ( $>3$ nuclei) cells were counted as osteoclasts. To calculate bone loss, the total CEJ-ABC distance of the 12 sites for the control side was subtracted from that of the same 12 sites for ligated side. To explore the cellular source of RANKL in periodontitis-induced bone loss, Tnfsf $11^{\text {flox }}$ flox mice or Tnfsf $11^{\text {flox/ } / \Delta}$ mice were crossed with Cre lines specific to B cells (Mb1-Cre), T cells (Cd4-Cre), osteoblastic cells ( $S p 7$-Cre), and periodontal ligament cells ( $S c x$ Cre). Sp7-Cre mice crossed with Tnfsf $11^{\text {flox/flox }}$ mice were treated from the prenatal period with Dox, which was withdrawn at the age of 3 weeks. Periodontitis was induced at the age of 8 weeks and alveolar bone was analyzed 10 days after the ligature placement in all groups. Mice in which the ligatures were lost were excluded from the data.

Analysis of oral bacterial dissemination. Three-week-old C57BL/6 wild-type female mice were fed with powder food and mice in all of the groups (Control, Ext, PD, PD-Ext) were co-housed for 6 weeks. A 5-0 silk ligature was tied around the maxillary second molar of mice in the PD and PD-Ext groups. The ligature was replaced every week and collected prior to sacrifice at day 42 in the PD group. After ligature placement for 2 weeks, the maxillary second molar was extracted using forceps in Ext and PD-Ext mice under anesthesia. We analyzed the closure of the extraction socket and bacterial colony formation in liver and spleen after 4 weeks of tooth extraction because it was reported that the extraction socket was completely covered by the epithelial tissue in 4 weeks after tooth loss ${ }^{60}$. The healing of oral mucosa and bacterial dissemination after tooth extraction normally finished in $117 a^{-/-} I l 17 f^{-/-}$mice as well as Il6raflox/flox Foxp3-Cre mice. The liver and spleen were sterilely collected and mechanically homogenized using Tissue homogenizing CKMix (Bertin Technologies) in sterile saline, and cultured on trypticase soy agar with $5 \%$ sheep blood (BD Bioscience) under an aerobic condition or CDC anaerobe blood agar (BD Bioscience) under an anaerobic condition for 2 days at $37^{\circ} \mathrm{C}$. The ligature was removed to analyze the bacterial composition under anesthesia just before sacrifice, and bacterial DNA was extracted and analyzed as shown in the following.

$16 S$ rRNA gene sequencing. Bacterial DNA was extracted from the ligature, fecal samples and tissue cultures with a NucleoSpin ${ }^{\boxplus}$ Tissue Kit (Takara). The V4 region of $16 \mathrm{~S}$ rRNA genes was PCR amplified (25 cycles, primer pair F515/R806), followed by barcoding (eight cycles) using a Nextera XT Index Kit v2 (Illumina) in triplicate. Barcoded amplicons were sequenced (150-bp paired-end sequencing) on an Illumina MiSeq (Illumina). Sequenced paired-end reads were imported into CLC Genomics Workbench v.9.0 (CLC). Paired-end reads were merged, trimmed, and clustered into operational taxonomic units (OTUs) (97\%) by reference-based OTU clustering using Greengenes v13_5. Then the $\beta$-diversity was calculated. The primers were as follows: F515, 5'-GTGCCAGCMGCCGCGGTAA-3' and R806, 5' GGACTACHVGGGTWTCTAAT-3'. Mice were co-housed for at least 1 week before analysis.

Evaluation of the total bacterial load. To evaluate the total bacterial load in the oral cavity, the bacterial DNA extracted from ligature was amplified with a Bacteria (tuf gene) Quantitative PCR Kit (Takara). Real-time quantitative reverse transcription PCR (RT-PCR) analysis for the tuf gene was performed with an initial denaturation step of $95^{\circ} \mathrm{C}$ for $30 \mathrm{~s}$, followed by 40 cycles of $95^{\circ} \mathrm{C}$ for $5 \mathrm{~s}, 55^{\circ} \mathrm{C}$ for $30 \mathrm{~s}$, and $72^{\circ} \mathrm{C}$ for $30 \mathrm{~s}$ using SYBR Green (Toyobo) with a LightCycler (Roche). The tuf gene copy number was normalized with the ligature length.

Quantitative RT-PCR analysis. Real-time quantitative RT-PCR analysis was performed with a LightCycler (Roche) using SYBR Green (Toyobo). The level of mRNA expression was normalized with Gapdh expression. The following primers

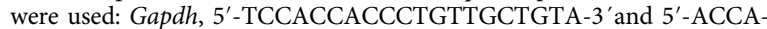

CAGTCCATGCCATCAC-3'; Tnfs $f 11,5^{\prime}$-AGCCATTTGCACACCTCAC-3' and 5'-CGTGGTACCAAGAGGACAGAGT-3'; Ill7a, 5' -TCCCTCTGTGATCTGGGAAG- $3^{\prime}$ and $5^{\prime}$-AGCATCTTCTCGACCCTGAA-3'; Ill7f, 5' ${ }^{\prime}$-CAAAAC-

CAGGGCATTTCTGT- $3^{\prime}$ and $5^{\prime}$-ATGGTGCTGTCTTCCTGACC- $3^{\prime} ; I l 1 b, 5^{\prime}$ CAGGCAGGCAGTATCACTCA- $3^{\prime}$ and 5'-AGGTGCTCATGTCCTCATCC-3'; Il4, $5^{\prime}$ - CCTCACAGCAACGAAGAACA- ${ }^{\prime}$ and 5' - ATCGAAAAGCCCGAAAGAGT-3'; Ifng, 5' - GCGTCATTGAATCACACCTG-3' and 5' - TGAGCTCATTGAATGCTTGG-3'; Tnfa, 5' - GCTGAGCTCAAACCCTGGTA- ${ }^{\prime}$ and $5^{\prime}$ CGGACTCCGCAAAGTCTAAG-3'; Il6, 5' - CCGGAGAGGAGACTTCACAG-3' and $5^{\prime}$ - CAGAATTGCCATTGCACAAC-3'; Rorc, 5' -TGCAAGACTCATCGACAAGG-3' and 5' - AGGGGATTCAACATCAGTGC-3'; Defb1, 5' AGGTGTTGGCATTCTCACAAG-3' and 5' - GCTTATCTGGTTTACAGGTTCCC-3'; Defb4, 5' - GCAGCCTTTACCCAAATTATC-3' and $5^{\prime}-$ ACAATTGCCAATCTGTCGAA-3'; $\mathrm{Cxcl1}, 5^{\prime}$ CGCTTCTCTGTGCAGCGCTGCT- $3^{\prime}$ and $5^{\prime}$ - CAAGCCTCGCGACCATTCTTGA-3'; Cxcl2, 5' - TCCAGAGCTTGAGTGTGACG-3' and 5'TCCAGGTCAGTTAGCCTTGC- $3^{\prime}$. The periodontal tissues were collected from the maxilla as described previously ${ }^{61}$, and homogenized using Tissue homogenizing CKMix (Bertin Technologies) in TRIzol (Life technologies) to extract the total RNA.

In situ hybridization. Periodontal tissues were fixed with G-Fix (Genostaff), decalcified with G-Chelate Mild (Genostaff), embedded in paraffin on a CT-Pro20 (Genostaff) using G-Nox (Genostaff) as a less toxic organic solvent for xylene, and 
sectioned at 5-8 $\mu \mathrm{m}$. In situ hybridization was performed with the ISH Reagent Kit (Genostaff) according to the manufacturer's instructions. Tissue sections were deparaffined with G-Nox, and rehydrated through an ethanol series and phosphatebuffered saline (PBS). The sections were fixed with $10 \%$ NBF (10\% formalin in PBS) for $30 \mathrm{~min}$ at $37^{\circ} \mathrm{C}$ and washed in distilled water, placed in $0.2 \mathrm{~N} \mathrm{HCl}$ for 10 min at $37^{\circ} \mathrm{C}$ and washed in PBS, treated with $4 \mu \mathrm{g} \mathrm{ml}^{-1}$ ProteinaseK (Wako Pure Chemical Industries) in PBS for $10 \mathrm{~min}$ at $37^{\circ} \mathrm{C}$ and washed in PBS, then placed within a coplin jar containing $1 \times$ G-Wash (Genostaff), equal to 1xSSC. Hybridization was performed with probes at concentrations of $250 \mathrm{ng} \mathrm{ml}^{-1}$ in G-Hybo-L (Genostaff) for $16 \mathrm{~h}$ at $60^{\circ} \mathrm{C}$. After hybridization, the sections were washed in $1 \mathrm{xG}$ Wash for $10 \mathrm{~min}$ at $60^{\circ} \mathrm{C}, 50 \%$ formamide in $1 \mathrm{xG}$-Wash for $10 \mathrm{~min}$ at $60^{\circ} \mathrm{C}$. Then the sections were washed twice in $1 \mathrm{xG}-\mathrm{W}$ ash for $10 \mathrm{~min}$ at $60^{\circ} \mathrm{C}$, twice in $0.1 \mathrm{xG}$ Wash for $10 \mathrm{~min}$ at $60^{\circ} \mathrm{C}$ and twice in TBST $(0.1 \%$ Tween 20 in tris-buffered saline (TBS)) at room temperature (RT). After treatment with $1 \times$ G-Block (Genostaff) for $15 \mathrm{~min}$ at RT, the sections were incubated with anti-DIG AP conjugate (Roche Diagnostics) diluted 1:2000 with x50G-Block (Genostaff) in TBST for $1 \mathrm{~h}$ at RT. The sections were washed twice in TBST and then incubated in $100 \mathrm{mM} \mathrm{NaCl}, 50$ $\mathrm{mM} \mathrm{MgCl} 2,0.1 \%$ Tween 20, $100 \mathrm{mM}$ Tris-HCl, $\mathrm{pH}$ 9.5. Coloring reactions were performed with NBT/BCIP solution (Sigma-Aldrich) overnight and then the samples were washed in PBS. The sections were counterstained with Kernechtrot stain solution (Muto Pure Chemicals), and mounted with G-Mount (Genostaff). The probes for Tnfsf11 and Il6 were purchased from Genostaff.

Flow cytometry and antibodies. Antibodies conjugated with biotin, FITC, Alexa Fluor 488, phycoerythrin (PE), PerCP-Cy5.5, allophycocyanin (APC), and pacific blue $(\mathrm{PB})$ were used at a 1:100 dilution unless otherwise mentioned. The following monoclonal antibodies were purchased from eBioscience: anti-human CD2 (RPA2.10), anti-mouse CD4 (RM4-5), CD25 (PC61), CD39 (24DMS1), CD44 (IM7), CD62L (also called SELL) (MEL-14), CD103 (2E7), OX40 (also called CD134) (OX-86), GITR (also called CD357) (DTA-1, 1:1600), T-cell receptor- $\beta$ (TCR- $\beta$ ) (H57-597), CCR6 (140706), RANKL (IK22/5), KLRG1 (2F1), FR4 (eBio12A5, 1:400), Foxp3 (FJK-16s), CTLA-4 (UC10-4B9), IFN- $\gamma$ (XMG1.2), IL-4 (11B11), and IL-17A (eBio17B7). Anti-Helios (22F6) was purchased from BioLegend. Goat anti-mouse/rat Nrp1 (FAB566N, 1:40) was purchased from R\&D Systems. The Foxp3 Staining Buffer Set (eBioscience) was used for intracellular Foxp3 staining. For intracellular cytokine staining, cells were stimulated with $50 \mathrm{ng} \mathrm{ml}^{-1}$ phorbol myristate acetate (Sigma-Aldrich), $500 \mathrm{ng} \mathrm{ml}^{-1}$ ionomycin (Sigma-Aldrich) and GolgiPlug (BD Biosciences) for $5 \mathrm{~h}$. After washing, cells were stained for surface antigens, fixed with $4 \%$ paraformaldehyde (Nacalai Tesque) for $10 \mathrm{~min}$ at room temperature, and then permeabilized and stained with monoclonal antibodies to cytokine diluted in Perm/Wash buffer (BD Biosciences). Flow cytometric analysis was performed using FACSCanto II with Diva software (BD Biosciences). Periodontal tissues were prepared as described previously ${ }^{61}$. FACS analysis was performed 7 days after placement of the ligature unless otherwise indicated.

Adoptive transfer. Single-cell suspensions were obtained from peripheral lymph nodes (LNs) and the spleen of periodontitis-induced Foxp $3^{h C D 2}$ IL-17-GFP reporter mice 7 days after the ligature placement. Splenic erythrocytes were eliminated with red blood cell lysis buffer (Sigma-Aldrich). To purify the peripheral CD4 ${ }^{+} \mathrm{T}$-cell subpopulation, the pooled spleen and LN cells were subjected to a depletion of adherent cells by panning with goat anti-mouse IgG Fc (Cappel, 55472, 1:200) and stained with PE-conjugated mouse anti-human CD2 (RPA-210, eBioscience, $1: 100)$. Cells were then incubated with anti-PE microbeads (Miltenyi Biotech) and separated on LS columns (Miltenyi Biotech). The hCD2 ${ }^{+}$or $\mathrm{hCD}^{-}$cells were further stained with anti-CD4, anti-CD44, and anti-CD62L monoclonal antibodies, and subjected to FACS sorting using FACSAria III (BD Biosciences). Naive CD $44^{\text {lo }}{ }^{\circ}$ 62 $2 \mathrm{~L}^{\text {hi }}$ Foxp $33^{\text {hCD2 } 2}$ CD $4{ }^{+}$T cells and $\mathrm{CD} 4{ }^{+}$Foxp $3{ }^{\text {hCD2 } 2} \mathrm{~T}$ cells were collected and then cultured in Iscove's modified Dulbecco's medium (SigmaAldrich) supplemented with $2 \mathrm{mM}$ L-glutamine, 10\% FBS, $50 \mu \mathrm{M} 2-\mathrm{ME}$, $100 \mathrm{U} \mathrm{ml}^{-1}$ penicillin, and $100 \mathrm{\mu g} \mathrm{ml}^{-1}$ streptomycin in the presence of $10 \mathrm{ng} \mathrm{ml}^{-1}$ recombinant mouse IL-1 $\beta$ (rmIL-1 $\beta$ ) (R\&D Systems), $100 \mathrm{ng} \mathrm{ml}^{-1} \mathrm{rmIL}-6$ (PeproTech), $50 \mathrm{ng} \mathrm{ml}^{-1}$ rmIL-23 (R\&D Systems), $5 \mathrm{ng} \mathrm{ml}^{-1}$ recombinant human transforming growth factor- $\beta 1$ (rhTGF- $\beta 1$ ) (R\&D Systems), $5 \mu \mathrm{g} \mathrm{ml}^{-1}$ anti-IFN- $\gamma$ (XMG1.2, BD Biosciences), $5 \mu \mathrm{g} \mathrm{ml}^{-1}$ anti-IL-4 (11B11, BD Biosciences) and beads coated with monoclonal antibodies to CD3 and CD28 (Dynal; $25 \mu \mathrm{l}$ per $1 \times 10^{6}$ cells) for 4 days. Foxp $3^{\text {hCD2-}}{ }^{2}$ IL-17-GFP ${ }^{+}$cells were then sorted as conventional $\mathrm{T}_{\mathrm{H}} 17$ cells and exFoxp $3 \mathrm{~T}_{\mathrm{H}} 17$ cells, respectively. The sorted cells were subsequently subjected to adoptive transfer experiments or analysis of their characteristics by FACS and RT-PCR. Adoptive transfer was achieved by a vein injection of $3 \times 10^{4}$ cells into $\mathrm{Tcra}^{-/-}$mice just before ligature placement.

Statistical analyses. Data were analyzed on GraphPad Prism software version 6.0 g. Statistical tests, $n$-values, replicate experiments, and $P$-values are all located in the figures and/or legends. All data are expressed as the mean \pm s.e.m. $P$-values were calculated using Student's $t$-test, analysis of variance (ANOVA) with Dunnett's or Tukey's multiple-comparison test, or permutational ANOVA (PERMANOVA) of the weighted UniFrac distance $\left({ }^{*} P<0.05 ;{ }^{*} P<0.01 ;{ }^{* *} P<0.005\right.$; NS, not significant, throughout the paper). We estimated the sample size considering the variation and mean of the samples. Neither randomization nor blinding was done in this study. Statistical tests are justified as appropriate for every figure, and the data meet the assumptions of the tests.

Data availability. Sequence data that support the findings of this study have been deposited in the NCBI Gene Expression Omnibus (GEO) database with the primary accession code GSE109664.

Received: 21 August 2017 Accepted: 24 January 2018

Published online: 16 February 2018

\section{References}

1. Round, J. L. \& Mazmanian, S. K. The gut microbiota shapes intestinal immune responses during health and disease. Nat. Rev. Immunol. 9, 313-323 (2009).

2. Bosshardt, D. D. \& Lang, N. P. The junctional epithelium: from health to disease. J. Dent. Res. 84, 9-20 (2005).

3. Hajishengallis, G. Immunomicrobial pathogenesis of periodontitis: keystones, pathobionts, and host response. Trends Immunol. 35, 3-11 (2014).

4. Miller, W. D. The human mouth as a focus of infection. Lancet 138, 340-342 (1891).

5. O'Reilly, P. G. \& Claffey, N. M. A history of oral sepsis as a cause of disease. Periodontol. 2000. 23, 13-18 (2000).

6. Hajishengallis, G. Periodontitis: from microbial immune subversion to systemic inflammation. Nat. Rev. Immunol. 15, 30-44 (2015).

7. Olsen, I. Update on bacteraemia related to dental procedures. Transfus. Apher. Sci. 39, 173-178 (2008).

8. Wade, W. G. The oral microbiome in health and disease. Pharmacol. Res. 69, 137-143 (2013)

9. Han, Y. W. \& Wang, X. Mobile microbiome: oral bacteria in extra-oral infections and inflammation. J. Dent. Res. 92, 485-491 (2013).

10. Ishigame, $\mathrm{H}$. et al. Differential roles of interleukin-17A and $-17 \mathrm{~F}$ in host defense against mucoepithelial bacterial infection and allergic responses. Immunity 30, 108-119 (2009).

11. Iwakura, Y., Ishigame, H., Saijo, S. \& Nakae, S. Functional specialization of interleukin-17 family members. Immunity 34, 149-162 (2011).

12. Takayanagi, H. New developments in osteoimmunology. Nat. Rev. Rheumatol. 8, 684-689 (2012).

13. Okamoto, K. et al. Osteoimmunology: The conceptual framework unifying the immune and skeletal systems. Physiol. Rev. 97, 1295-1349 (2017).

14. Komatsu, N. et al. Pathogenic conversion of Foxp $3^{+} \mathrm{T}$ cells into $\mathrm{T}_{\mathrm{H}} 17$ cells in autoimmune arthritis. Nat. Med. 20, 62-68, (2014).

15. Hirota, K. et al. Fate mapping of IL-17-producing T cells in inflammatory responses. Nat. Immunol. 12, 255-263 (2011).

16. Gagliani, $N$. et al. $\mathrm{T}_{\mathrm{H}} 17$ cells transdifferentiate into regulatory $\mathrm{T}$ cells during resolution of inflammation. Nature 523, 221-225 (2015).

17. Massoud, A. H. et al. An asthma-associated IL4R variant exacerbates airway inflammation by promoting conversion of regulatory $\mathrm{T}$ cells to $\mathrm{T}_{\mathrm{H}} 17$-like cells. Nat. Med. 22, 1013-1022 (2016).

18. Bailey-Bucktrout, S. L. et al. Self-antigen-driven activation induces instability of regulatory $\mathrm{T}$ cells during an inflammatory autoimmune response. Immunity 39, 949-962 (2013).

19. Zhou, X. et al. Instability of the transcription factor Foxp3 leads to the generation of pathogenic memory T cells in vivo. Nat. Immunol. 10, 1000-1007 (2009).

20. Abe, T. \& Hajishengallis, G. Optimization of the ligature-induced periodontitis model in mice. J. Immunol. Methods 394, 49-54 (2013).

21. Teng, Y. T. et al. Functional human T-cell immunity and osteoprotegerin ligand control alveolar bone destruction in periodontal infection. J. Clin. Invest. 106, R59-R67 (2000).

22. Dutzan, N. et al. On-going mechanical damage from mastication drives homeostatic $\mathrm{T}_{\mathrm{H}} 17$ cell responses at the oral barrier. Immunity 46, 133-147 (2017).

23. Ono, T. et al. IL-17-producing $\gamma \delta \mathrm{T}$ cells enhance bone regeneration. Nat. Commun. 7, 10928 (2016)

24. Ivanov, I. I. et al. Specific microbiota direct the differentiation of IL-17producing T-helper cells in the mucosa of the small intestine. Cell Host Microbe 4, 337-349 (2008).

25. Ivanov, I. I. et al. Induction of intestinal $\mathrm{T}_{\mathrm{H}} 17$ cells by segmented filamentous bacteria. Cell 139, 485-498 (2009).

26. Sano, T. et al. An IL-23R/IL-22 circuit regulates epithelial serum amyloid a to promote local effector $\mathrm{T}_{\mathrm{H}} 17$ responses. Cell 164, 324 (2016).

27. Tomura, M. et al. Tracking and quantification of dendritic cell migration and antigen trafficking between the skin and lymph nodes. Sci. Rep. 4, 6030 (2014).

28. Takahashi, N. et al. Osteoblastic cells are involved in osteoclast formation Endocrinology 123, 2600-2602 (1988).

29. Kanzaki, H. et al. Soluble RANKL cleaved from activated lymphocytes by TNF- $\alpha$-converting enzyme contributes to osteoclastogenesis in periodontitis. J. Immunol. 197, 3871-3883 (2016). 
30. Nagashima, K. et al. Identification of subepithelial mesenchymal cells that induce IgA and diversify gut microbiota. Nat. Immunol. 18, 675-682 (2017).

31. Chen, B. et al. RANKL expression in periodontal disease: where does RANKL come from? Biomed. Res. Int. 2014, 731039 (2014).

32. Xiong, J. et al. Matrix-embedded cells control osteoclast formation. Nat. Med. 17, 1235-1241 (2011).

33. Terashima, A. et al. Sepsis-induced osteoblast ablation causes immunodeficiency. Immunity 44, 1434-1443 (2016).

34. Sato, $\mathrm{K}$. et al. $\mathrm{T}_{\mathrm{H}} 17$ functions as an osteoclastogenic helper $\mathrm{T}$ cell subset that links $\mathrm{T}$ cell activation and bone destruction. J. Exp. Med. 203, 2673-2682 (2006).

35. Lin, D. et al. IL-17 regulates the expressions of RANKL and OPG in human periodontal ligament cells via TRAF6/TBK1-JNK/NF-kB pathways. Immunology https://doi.org/10.1111/imm.12395 (2014).

36. Easlick, K. A. An evaluation of the effect of dental foci of infection on health. $J$. Am. Dent. Assoc. 42, 615-697 (1951).

37. Oğütcen-Toller, M. et al. Intractable bimaxillary osteomyelitis in osteopetrosis: review of the literature and current therapy. J. Oral Maxillofac. Surg. 68, 167-175 (2010).

38. Khan, A. A. et al. Diagnosis and management of osteonecrosis of the jaw: a systematic review and international consensus. J. Bone Miner. Res. 30, 3-23 (2015).

39. Otto, S. et al. Tooth extraction in patients receiving oral or intravenous bisphosphonate administration: A trigger for BRONJ development? J. Craniomaxillofac. Surg. 43, 847-854 (2015).

40. Aguirre, J. I. et al. Oncologic doses of zoledronic acid induce osteonecrosis of the jaw-like lesions in rice rats (Oryzomys palustris) with periodontitis. J. Bone Miner. Res. 27, 2130-2143 (2012).

41. Dutzan, N., Konkel, J. E., Greenwell-Wild, T. \& Moutsopoulos, N. M. Characterization of the human immune cell network at the gingival barrier. Mucosal Immunol. 9, 1163-1172 (2016).

42. Zenobia, C. \& Hajishengallis, G. Basic biology and role of interleukin-17 in immunity and inflammation. Periodontol. 2000. 69, 142-159 (2015).

43. Okui, T., Aoki, Y., Ito, H., Honda, T. \& Yamazaki, K. The presence of IL-17 ${ }^{+} / \mathrm{FOXP}^{+}{ }^{+}$double-positive cells in periodontitis. J. Dent. Res. 91, 574-579 (2012).

44. Kobayashi, T. et al. Assessment of interleukin-6 receptor inhibition therapy on periodontal condition in patients with rheumatoid arthritis and chronic periodontitis. J. Periodontol. 85, 57-67 (2014).

45. Yamaji, Y. et al. Inflammatory cytokine gene expression in human periodontal ligament fibroblasts stimulated with bacterial lipopolysaccharides. Infect. Immun. 63, 3576-3581 (1995).

46. Sun, Y., Shu, R., Li, C. L. \& Zhang, M. Z. Gram-negative periodontal bacteria induce the activation of toll-like receptors 2 and 4 , and cytokine production in human periodontal ligament cells. J. Periodontol. 81, 1488-1496 (2010).

47. Jeon, D. I. et al. NOD1 and NOD2 stimulation triggers innate immune responses of human periodontal ligament cells. Int. J. Mol. Med. 29, 699-703 (2012).

48. Andrukhov, O. et al. Response of human periodontal ligament stem cells to IFN-g and TLR-agonists. Sci. Rep. 7, 12856 (2017).

49. Jian, C. et al. Hypoxia augments lipopolysaccharide-induced cytokine expression in periodontal ligament cells. Inflammation 37, 1413-1423 (2014).

50. Guan, S. M., Zhang, M., He, J. J. \& Wu, J. Z. Mitogen-activated protein kinases and phosphatidylinositol 3-kinase are involved in Prevotella intermediainduced proinflammatory cytokines expression in human periodontal ligament cells. Biochem. Biophys. Res. Commun. 386, 471-476 (2009).

51. Reisz, R. R., Scott, D. M., Pynn, B. R. \& Modesto, S. P. Osteomyelitis in a Paleozoic reptile: ancient evidence for bacterial infection and its evolutionary significance. Naturwissenschaften 98, 551-555 (2011).

52. Vivier, E., van de Pavert, S. A., Cooper, M. D. \& Belz, G. T. The evolution of innate lymphoid cells. Nat. Immunol. 17, 790-794 (2016).

53. Miyao, T. et al. Plasticity of Foxp $3^{+} \mathrm{T}$ cells reflects promiscuous Foxp3 expression in conventional $\mathrm{T}$ cells but not reprogramming of regulatory T cells. Immunity 36, 262-275 (2012).

54. Takimoto, A. et al. Scleraxis and osterix antagonistically regulate tensile forceresponsive remodeling of the periodontal ligament and alveolar bone. Development 142, 787-796 (2015).

55. Sugimoto, Y., Takimoto, A., Hiraki, Y. \& Shukunami, C. Generation and characterization of ScxCre transgenic mice. Genesis 51, 275-283 (2013).

56. Lee, P. P. et al. A critical role for Dnmtl and DNA methylation in T cell development, function, and survival. Immunity 15, 763-774 (2001).
57. Hobeika, E. et al. Testing gene function early in the B cell lineage in mb1-cre mice. Proc. Natl Acad. Sci. USA 103, 13789-13794 (2006).

58. Mombaerts, P. et al. Mutations in T-cell antigen receptor genes alpha and beta block thymocyte development at different stages. Nature 360, 225-231 (1992)

59. de Boer, J. et al. Transgenic mice with hematopoietic and lymphoid specific expression of Cre. Eur. J. Immunol. 33, 314-325 (2003).

60. Park, S. et al. Osteonecrosis of the jaw developed in mice: Disease variants regulated by $\gamma \delta \mathrm{T}$ cells in oral mucosal barrier immunity. J. Biol. Chem. 290, 17349-17366 (2015)

61. Mizraji, G., Segev, H., Wilensky, A. \& Hovav, A. H. Isolation, processing and analysis of murine gingival cells. J. Vis. Exp. 77, e50388 (2013).

\section{Acknowledgements}

We are grateful to S. Hori (The University of Tokyo), J.A. Bluestone (University of California, San Francisco), M. Reth (Max Planck Institute) and M. Tomura (Osaka Ohtani University) for providing Foxp $3^{h C D 2}$ knock-in mice ${ }^{53}$, Foxp3-GFP-Cre mice ${ }^{19}$, Mb1-Cre mice ${ }^{57}$, and ROSA-CAG-lox-stop-lox-hKikGR mice[27], respectively. $\operatorname{Tnfs}_{s} 11^{\Delta \mathrm{S} / \Delta \mathrm{S}}$ mice were generated by T. Okamura (National Center for Global Health and Medicine). We are grateful to Chugai Pharmaceutical Co. for providing anti-IL-6R antibody (MR16-1). We thank S. Sawa, T. Negishi-Koga, A. Terashima, H. Takaba, R Muro, S.J. Win, T. Ono, Y. Nakai, Y. Ogiwara, K. Kusubata, S. Nitta, Y. Nakayama, T. Abe, and H. Odanaka for discussion and assistance. This work was supported in part by a grant for the Grants-in-Aid for Specially Promoted Research (15H05703), Young Scientists A (26713015) (15H05653) and Challenging Exploratory Research (16K15252) from the Japan Society for the Promotion of Science (JSPS), a grant for Practical Research Project for Rare/Intractable Diseases (JP17ek0109106) from Japan Agency for Medical Research and Development, and grants from the Kanae foundation for the promotion of medical science, the Uehara Memorial Foundation, and Kowa Life Science Foundation M.T. was supported by a JSPS Research Fellowship for Young Scientists (15J05324).

\section{Author contributions}

M.T. designed and performed most of the experiments, interpreted the results, and prepared the manuscript. N.K. provided advice on project planning and data interpretation. K.N. and W.P. contributed to the experiments and data interpretation. T.Nitta, C.S., Y.I., and T.Nakashima provided genetically modified mice and contributed to data interpretation. K.O. provided advice on project planning and data interpretation. H.T. directed the project and wrote the manuscript.

\section{Additional information}

Supplementary Information accompanies this paper at https://doi.org/10.1038/s41467 018-03147-6.

Competing interests: K.O. declares that the Department of Osteoimmunology, Graduate School of Medicine and Faculty of Medicine, The University of Tokyo in which he works is an endowmentdepartment, supported with an unrestricted grant from Chugai Pharmaceutical Co.,751 LTD., AYUMI Pharmaceutical Corporation and Noevir Co., Ltd. The remaining authors declare no competing financial interests.

Reprints and permission information is available online at http://npg.nature.com/ reprintsandpermissions/

Publisher's note: Springer Nature remains neutral with regard to jurisdictional claims in published maps and institutional affiliations.

Open Access This article is licensed under a Creative Commons Attribution 4.0 International License, which permits use, sharing, adaptation, distribution and reproduction in any medium or format, as long as you give appropriate credit to the original author(s) and the source, provide a link to the Creative Commons license, and indicate if changes were made. The images or other third party material in this article are included in the article's Creative Commons license, unless indicated otherwise in a credit line to the material. If material is not included in the article's Creative Commons license and your intended use is not permitted by statutory regulation or exceeds the permitted use, you will need to obtain permission directly from the copyright holder. To view a copy of this license, visit http://creativecommons.org/ licenses/by/4.0/

(C) The Author(s) 2018 